\title{
CLEO/QELS 2010
}

\section{Laser Science to Photonic Applications}

Technical Conference: May 16-21, 2010

Expo: May 18-20 2011

Short Courses: May 16-18 2011

San Jose Convention Center, San Jose, California, USA

This year's program featured more than 1,700 presentations in technical hot topics:

- ultrafast optics

- energy-efficient photonics

- semiconductor lasers

- nanophotonics

- biophotonics

Breakthrough papers were presented, such as new laser techniques for cooling semiconductors, using the world's most powerful x-ray system to probe molecules - and a new metamaterial device that could someday lead to see-through cameras.

The CLEO: Applications program focused on the demonstration of components, systems, and emerging applications of lasers and electro-optical technology.

Timely topics: energy and the environment, biotechnology, defense and security, and industrial manufacturing.

CLEO: Applications presentations delved deep into today's existing and evolving commercial and business applications.

Also on the show floor, the CLEO: Market Focus program featured business development and commercialized applications in energy, industrial lasers, defense and security, and biophotonics.

New this year, the CLEO: Technology Transfer Showcase offered a -one-stop\| way to learn about the latest optics and photonics technologies coming out of universities and government labs. What they foretell - new commercial products or improvements in the efficiency, durability and availability of existing components or systems. 
These well-attended programs complemented cutting-edge products and demos on the show floor. The field's leading global companies showcased the latest in photonics technology and services.

LaserFest, the 50th anniversary of the laser, was celebrated with special events throughout the week. CLEO/QELS: 2010 kicked off exactly 50 years after the first laser demonstration by Theodore Maiman at Hughes Research Labs on May 16, 1960.

A special symposium featuring several laser pioneers, Nobel Laureates, historians and experts was held May 16.

At the LaserFest Pavilion on the show floor, attendees could view a display of more than 100 lasers from the past 50 years and see a live demonstration of an early ruby laser.

Tuesday night celebrated LasersRock! musical entertainment provided by fellow CLEO/QELS colleagues.

President Obama sent a message to CLEO/QELS attendees recognizing the laser as "one of the most important and versatile inventions of the 20th century."

The conference co-sponsors-APS, IEEE Photonics Society, and OSA - thank all of those who participated in the 2010 programs and activities. CLEO/QELS continues to be the mustattend event for cutting-edge technical programming in the lasers, electro-optics and photonics industry.

\section{Conference Program}

CLEO/QELS features industry leaders in the fields of lasers, optical devices, optical fibers, photonics and innovative approaches in such fields as: laser spectroscopy, maser, nonlinear optics, optical detectors, optical modulators, optical pulses and quantum mechanics.

\section{CLEO/QELS Abstracts}

Monday, May 17, 2010

$\underline{\text { Tuesday, May 18, } 2010}$

$\underline{\text { Wednesday, May 19, } 2010}$

Thursday, May 20, 2010

Friday, May 21, 2010 
$\underline{\text { Postdeadline Paper Abstracts }}$

Agenda of Sessions and Key to Authors and Presiders

Agenda of Sessions

$\underline{\text { Key to Authors and Presiders }}$

Postdeadline Paper Key to Authors and Presiders

Committees

CLEO/QELS Committees

\section{CLEO General Co-Chairs}

Claire Gmachl, Princeton Univ., USA

Konstantin Vodopyanov, Stanford Univ., USA

\section{CLEO Program Co-Chairs}

Robert Fisher, R. A. Fisher Associates, USA

Paul Juodawlkis, MIT Lincoln Lab, USA

\section{CLEO 01 - Laser Processing of Materials: Fundamentals and Applications}

Craig Arnold, Princeton Univ., USA, Chair

Tommaso Baldacchini, Newport Corp., USA

Malcolm Gower, Nanophoton Technologies, UK

Richard Haglund, Vanderbilt Univ., USA

Yves Hernandez, Multitel Corp., Belgium

Minghui Hong, Data Storage Inst., Singapore

Thomas Lippert, Paul Scherer Inst., Switzerland

Eric Mottay, Amplitude Systèmes, France

Hiroyuki Niino, Photonics Res. Inst., AIST, Japan

Leslie Phinney, Sandia Natl. Labs, USA

Razvan Stoian, Univ. Jean Monnet, France

Steve Yalisove, Univ. of Michigan, USA

\section{CLEO 02 - Solid-State, Liquid and Gas Lasers}


Daniel J. Ripin, MIT Lincoln Lab, USA, Chair

William J. Alford, Lockheed Martin, USA

Andy J. Bayramian, Lawrence Livermore Natl. Lab, USA

Gregory D. Goodno, Northrop Grumman Corp., USA

Joachim Hein, Friedrich-Schiller-Univ. Jena, Germany

Eric Honea, Lockheed Martin Aculight, USA

Junji Kawanaka, Osaka Univ., Japan

Dietmar Kracht, Laser Zentrum Hannover e.V., Germany

Steven Massey, AFRL, USA

Ara Minassian, Midaz Lasers Ltd., UK Jesper

Munch, Univ. of Adelaide, Australia Ramesh

Shori, Naval Air Systems Command, USA

\section{CLEO 03 - Semiconductor Lasers}

Peter Smowton, Cardiff Univ., UK, Chair

David Roh, Coherent Inc., USA, Alternate Chair

Seth Bank, Univ. of Texas at Austin, USA

A. Catrina Bryce, Univ. of Glasgow, UK

In Kim, Samsung Electronics Co., Republic of Korea

Hui Liu, Natl. Res. Council Canada, Canada

Richard Mirin, NIST, USA

Nobuhiko Nishiyama, Tokyo Inst. of Technology, Japan

James J. Raftery, US Military Acad., USA

Shinji Tsuji, Hitachi Central Res. Lab, Japan

Daniel Wasserman, Univ. of Massachusetts at Lowell, USA

Dan Yanson, Semi Conductor Devices Ltd., Israel

\section{CLEO 04 - Applications of Nonlinear Optics}

Narasimha S. Prasad, NASA Langley Res. Ctr., USA, Chair

Darrell Armstrong, Sandia Natl. Labs, USA

Arnaud Brignon, Thales Res. and Technology, France

Gary Catella, Cleveland Crystals, Inc., USA

Judith M. Dawes, Macquarie Univ., Australia

Jason Fleischer, Princeton Univ., USA

Shekhar Guha, AFRL, USA

Takashige Omatsu, Chiba Univ., Japan

Andrew Schober, Lockheed Martin Coherent Technologies, USA

Andrew Scott, QinetiQ Ltd., UK

Vladimir V. Shkunov, Raytheon Corp., USA

\section{CLEO 05 - Terahertz Technologies and Applications}


Yujie J. Ding, Lehigh Univ., USA, Chair

Richard D. Averitt, Boston Univ., USA

Stefano Barbieri, Univ. of Paris VII, France

Jerry Chen, MIT Lincoln Lab, USA

Frank Hegmann, Univ. of Alberta, Canada

Manfred Helm, Forschungszentrum Dresden-Rossendorf, Germany

Iwao Hosako, NICT, Japan

Peter U. Jepsen, Technical Univ. of Denmark, Denmark

Kodo Kawase, Ecotopia Science Inst., Nagoya Univ., Japan

Ajay Nahata, Univ. of Utah, USA

Chi-Kuang Sun, Natl. Taiwan Univ., Taiwan

Weili Zhang, Oklahoma State Univ., USA

\section{CLEO 06 - Optical Materials, Fabrication and Characterization}

Sunao Kurimura, Natl. Inst. for Materials Science, Japan, Chair

Gerard Aka, École Natl. Superieure de Chimie de Paris, France

Myoungsik Cha, Pusan Natl. Univ., Republic of Korea

Stavros G. Demos, Lawrence Livermore Natl. Lab, USA

Masaki Harada, Nikon Corp., Japan

Aaron R. Hawkins, Brigham Young Univ., USA

Yushi Kaneda, Univ. of Arizona, USA

Anders Kristensen, Denmark Technical Univ., Denmark

Fredrik Laurell, Royal Inst. of Technology, Sweden

Haisheng Rong, Intel Corp., USA

Vladimir Shur, Univ. of Ural, Russian Federation

Masashi Yoshimura, Osaka Univ., Japan

\section{CLEO/QELS 07 - Joint Subcommittee on High-Field Physics and High-Intensity Lasers}

Craig Siders, Lawrence Livermore Natl. Lab, USA, Chair

David Villeneuve, Natl. Res. Council Canada, Canada, Junior Co-Chair

Szu-yuan Chen, Academia Sinica, Taiwan

Markus Drescher, Inst. für Experimentalphysik, Univ. Hamburg, Germany

Henry C. Kapteyn, JILA and Dept. of Physics, Univ. of Colorado at Boulder, USA

Katsumi Midorikawa, RIKEN, Japan

Christoph Niemann, Univ. of California at Los Angeles, USA

Ronald Ruth, Lyncean Technologies, LLC, USA

Giuseppe Sansone, Politecnico de Milano, Italy

Csaba Toth, Lawrence Berkeley Natl. Lab, USA

Koichi Yamakawa, Japan Atomic Energy Agency, Japan

Jonathan Zuegel, Univ. of Rochester, USA 


\section{CLEO 08 - Ultrafast Optics, Optoelectronics and Applications}

Sterling Backus, Kapteyn-Murnane Labs, USA, Chair

Jens Biegert, Inst. of Photonic Sciences, ICFO, Spain

Giulio Cerullo, Politecnico di Milano, Italy

Charles G. Durfee, Colorado School of Mines, USA

David M. Gaudiosi, Raydiance, Inc., USA

Per Johnsson, Lund Univ., Sweden

Daniel J. Kane, Mesa Photonics, USA

Catherine Le Blanc, École Polytechnique, France

François Légaré, INRS-EMT, Canada

Zhiwen Liu, Pennsylvania State Univ., USA

Tom Nelson, Sandia Natl. Labs, USA

Konstantinos Simeonidis, Max-Planck-Inst. für Kernphysik, Germany

Irina T. Sorokina, Norwegian Univ. of Science and Technology, Norway

\section{CLEO 09 - Components, Integration, Interconnects and Signal Processing}

David C. Hutchings, Univ. of Glasgow, UK, Chair

Solomon Assefa, IBM T.J. Watson Res. Ctr., USA

Erwin Chan, Univ. of Sydney, Australia

Marc Desmulliez, Heriot-Watt Univ., UK

Tetsuya Kawanishi, NICT, Japan

Paul Matthews, Northrop Grumman Corp., USA

Beatriz Ortega, Polytechnic Univ. of Valencia, Spain

David Plant, McGill Univ., Canada

Joyce Poon, Univ. of Toronto, Canada

Olav Solgaard, Stanford Univ., USA

Todd H. Stievater, NRL, USA

Ryo Takahashi, NTT Photonics Labs, Japan

\section{CLEO 10 - Biophotonics and Optofluidics}

Brian E. Applegate, Texas A\&M Univ., USA, Chair

Emmanuel Beaurepaire, École Polytechnique, France

Alberto Bilenca, Lehigh Univ., USA

Brett E. Bouma, Harvard Medical School and Massachusetts General Hospital, USA

Chen-Yuan Dong, Natl. Taiwan Univ., Taiwan

David Erickson, Cornell Univ., USA

Gregory Faris, SRI Intl., USA

Min Gu, Swinburne Univ. of Technology, Australia

Dennis L. Matthews, Univ. of California at Davis, USA 
Holger Schmidt, Univ. of California at Santa Cruz, USA

Siavash Yazdanfar, GE Global Res., USA

Seok-Hyun (Andy) Yun, Harvard Univ., USA

\section{CLEO 11 - Fiber Amplifiers, Lasers and Devices}

Ingmar Hartl, IMRA America, Inc., USA, Chair

Kazi S. Abedin, NICT, Japan

Jacques Albert, Carleton Univ., Canada

Richard Berdine, AFRL, USA

Martijn de Sterke, Univ. of Sydney, Australia

John Dudley, Univ. of Franche-Comté, France

Shibin Jiang, AdValue Photonics Inc., USA

Robert Jopson, Bell Labs, Alcatel-Lucent, USA

Ming-Jun Li, Corning Inc., USA

John Minelly, Coherent, Inc., USA Norihiko

Nishizawa, Osaka Univ., Japan Siddharth

Ramachandran, Boston Univ., USA

Thomas Schreiber, Fraunhofer Inst. Optik Feinmechanik, Germany

Hideyuki Sotobayashi, Aoyama Gakuin Univ., Japan

\section{CLEO 12 - Lightwave Communications and Optical Networks}

René-Jean Essiambre, Bell Labs, Alcatel-Lucent, USA, Chair

Govind Agrawal, Univ. of Rochester, USA

Alberto Bononi, Univ. degli Studi di Parma, Italy

David Caplan, MIT Lincoln Lab, USA

Hiroshi Ito, Kitasato Univ., Japan

Ken-ichi Kitayama, Osaka Univ., Japan

Ton Koonen, Eindhoven Univ. of Technology, Netherlands

Chang-Hee Lee, KAIST, Republic of Korea

Juerg Leuthold, Univ. of Karlsruhe, Germany

Natasha Litchinitser, SUNY Buffalo, USA

Curtis Menyuk, Univ. of Maryland, Baltimore County, USA

Alexei Pilipetskii, Tyco Telecommunications, USA

\section{CLEO 13 - Active Optical Sensing}

Terrence Meyer, Iowa State Univ., USA, Chair

Douglas J. Bamford, Physical Sciences Inc., USA

Joakim Bood, Lund Inst. of Technology, Sweden

Joseph Buck, Lockheed Martin Coherent Technologies, USA

Volker Ebert, Univ. of Heidelberg, Germany 
Gregory Fiechtner, US Dept. of Energy, USA

James Gord, AFRL, USA

Zuyuan He, Univ. of Tokyo, Japan

Lin Ma, Clemson Univ., USA

Sukesh Roy, Spectral Energies, LLC, USA

Azer Yalin, Colorado State Univ., USA

\section{CLEO 14 - Optical Metrology}

Jason Jones, Univ. of Arizona, USA, Chair

Kristan L. Corwin, Kansas State Univ., USA

Feng-Lei Hong, AIST, Japan

Chad Hoyt, Bethel Univ., USA

Tetsuya Ido, NICT, Japan

Erich Ippen, MIT, USA

David Jones, Univ. of British Columbia, Canada

Jin Jonghan, Korea Res. Inst. of Standards and Science (KRISS), Republic of Korea

Kazunori Naganuma, NTT Photonics Lab, Japan

Christopher W. Oates, NIST, USA

James Phillips, Harvard College Observatory, USA

Thomas R. Schibli, JILA, USA

Evgeni Sorokin, Vienna Univ. of Technology, Austria

Uwe Sterr, Physikalisch-Technische Bundesanstalt (PTB), Germany

\section{CLEO 15 - LEDs, Photovoltaics and Energy-Efficient (-Green\|) Photonics}

Michael Wraback, US ARL, USA, Chair

Nicolas Grandjean, École Polytechnique Fédérale de Lausanne, Switzerland

Andreas Hangleiter, Technische Univ. Braunschweig, Germany

Motoaki Iwaya, Meijo Univ., Japan

Hao-chung Kuo, Natl. Chiao Tung Univ., Taiwan

Theodore Moustakas, Boston Univ., USA

Ifor Samuel, Univ. of St. Andrews, UK

Leo J. Schowalter, Crystal IS, Inc., USA

James Speck, Univ. of California at Santa Barbara, USA

Yoshitaka Taniyasu, NTT Basic Res. Labs, Japan

\section{CLEO 16 - Micro- and Nano-Photonics Devices}

Keren Bergman, Columbia Univ., USA, Chair

Roel Baets, Univ. of Ghent, Belgium

Harold M. Chong, Univ. of Southampton, UK

Shanhui Fan, Stanford Univ., USA 
Marco Fiorentino, Hewlett Packard, USA William

Green, IBM T.J. Watson Res. Ctr., USA Siegfried

Janz, Natl. Res. Council Canada, Canada Michal

Lipson, Cornell Univ., USA

Tanya Monro, Univ. of Adelaide, Australia

Susumu Noda, Kyoto Univ., Japan

Milos A. Popovic, MIT, USA

Armand Rosenberg, NRL, USA

Michael Watts, Sandia Natl. Labs, USA

\section{QELS General Co-Chairs}

Aephraim Steinberg, Univ. of Toronto, Canada

Hailin Wang, Univ. of Oregon, USA

\section{QELS Program Co-Chairs}

Hui Cao, Yale Univ., USA

Hideo Mabuchi, Stanford Univ., USA

\section{QELS 01 - Quantum Optics of Atoms, Molecules and Solids}

Perry Rice, Miami Univ., USA, Chair

Michael Drewsen, Bohr Inst., Denmark

Peter Maunz, Univ. of Maryland at College Park, USA

Scott Parkins, Univ. of Auckland, New Zealand

Mark Saffman, Univ. of Wisconsin at Madison, USA

Glenn Solomon, NIST, USA

Ian Spielman, NIST, USA

Daniel Steck, Univ. of Oregon, USA

Werner Vogel, Inst. of Physics, Univ. of Rostock, Germany

\section{QELS 02 - Quantum Science, Engineering and Technology}

Norbert Lütkenhaus, Univ. of Waterloo, Canada, Chair

Juergen Eschner, Inst. of Photonic Sciences, ICFO, Spain

Mikhail Lukin, Harvard Univ., USA

Morgan W. Mitchell, Inst. of Photonic Sciences, ICFO, Spain 
Bill Munro, HP Labs, UK

Masahide Sasaki, NICT, Japan

Dick Slusher, Georgia Tech, USA

Ian Walmsley, Univ. of Oxford, UK

\section{QELS 03 - Metamaterials and Complex Media}

Mikhail Noginov, Norfolk State Univ., USA, Chair

Allan D. Boardman, Univ. of Salford, UK

Alexandra Boltasseva, Purdue Univ., USA

Aristide Dogariu, CREOL, School of Optics and Photonics, Univ. of Central Florida, USA

Viktor A. Podolskiy, Oregon State Univ., USA

A. Douglas Stone, Yale Univ., USA

\section{QELS 04 - Optical Interactions with Condensed Matter and Ultrafast Phenomena}

Jacob B. Khurgin, Johns Hopkins Univ., USA, Chair

Allan Bracker, NRL, USA

Weng Chow, Sandia Natl. Labs, USA

Jianming Dai, Rensselaer Polytechnic Inst., USA

Emmanuel Dupont, Natl. Res. Council Canada, Canada

Andreas Knorr, Technische Univ. Berlin, Germany

Cun-Zheng Ning, Arizona State Univ., USA

\section{QELS 05 - Nonlinear Optics and Novel Phenomena}

Demetrios Christodoulides, CREOL, Univ. of Central Florida, USA, Chair

Neil Broderick, Univ. of Southampton, UK

David Hagan, CREOL, Univ. of Central Florida, USA

Detlef Kip, Clausthal Univ. of Technology, Germany

Roberto Morandotti, INRS-EMT, Canada

Ewan Wright, Univ. of Arizona, USA

\section{QELS 06 - Nano-Optics and Plasmonics}

Gennady Shvets, Univ. of Texas at Austin, USA, Chair

Harald Giessen, Univ. of Stuttgart, Germany

Henri Lezec, NIST, USA

Willie J. Padilla, Boston College, USA

Oscar Painter, Caltech, USA

Michelle L. Povinelli, Univ. of Southern California, USA

Igor I. Smolyaninov, BAE Systems, USA 


\section{CLEO/QELS 07 - Joint Subcommittee on High-Field Physics and High-Intensity Lasers}

Craig Siders, Lawrence Livermore Natl. Lab, USA, Chair

David Villeneuve, Natl. Res. Council Canada, Canada, Junior Co-Chair

Szu-yuan Chen, Academia Sinica, Taiwan

Markus Drescher, Inst. für Experimentalphysik, Univ. Hamburg, Germany

Henry C. Kapteyn, JILA and Dept. of Physics, Univ. of Colorado at Boulder, USA

Katsumi Midorikawa, RIKEN, Japan

Christoph Niemann, Univ. of California at Los Angeles, USA

Giuseppe Sansone, Politecnico de Milano, Italy

Csaba Toth, Lawrence Berkeley Natl. Lab, USA

Koichi Yamakawa, Japan Atomic Energy Agency, Japan

Jonathan Zuegel, Univ. of Rochester, USA

\section{CLEO: Applications Committee}

\section{CLEO: Applications Chairs}

Timothy Carrig; Lockheed Martin, USA, CLEO: Applications Chair Gail Overton; Laser Focus World, USA, CLEO Market Focus Chair

Nick Traggis; Precision Photonics Corp., USA, CLEO Market Focus Co-Chair

\section{Applications Committee}

Leon Esterowitz, Natl. Science Foundation, USA

Iain T. McKinnie; Kapteyn Murnane Labs, USA

Vasilis Ntziachristos, Technical Univ. of Munich, Germany

Clifford R. Pollock; Cornell Univ., USA

Jinendra K. Ranka; DARPA, USA

Bryce Schumm; AFRL, USA

Don Seeley; High Energy Laser - Joint Technology Office (HEL-JTO), USA

James W. Tunnell, Univ. of Texas, USA

Christopher Wood; Precision Photonics Corp., USA

Wende Zhang; General Motors, USA

\section{Market Focus Committee}

Finlay Colville, Coherent Inc., USA

Bill Kozlovsky, Skyline Solar, USA

Keshav Kumar, Newport Corp., USA

Vern Schlie, Integral Laser Solutions, USA

Eric Takeuchi, Daylight Solutions, USA 


\section{CLEO/QELS Steering Committee}

\section{IEEE/Photonics Society}

Alan E. Willner, Univ. of Southern California, USA, Chair

James J. Coleman, Univ. of Illinois at Urbana-Champaign, USA

Alexander L. Gaeta, Cornell Univ., USA

Paul W. Juodawlkis, MIT Lincoln Lab, USA

Jerry R. Meyer, NRL, USA

\section{Optical Society of America}

Thomas F. Carruthers, NSF, USA

James R. Leger, Univ. of Minnesota, USA

Prem Kumar, Northwestern Univ., USA

Gregory J. Quarles, VLOC, USA

John J. Zayhowski, MIT Lincoln Lab, USA

APS/Division of Laser Science

Wendell T. Hill, Univ. of Maryland at College Park, USA

Michael G. Raymer, Univ. of Oregon, USA

Exhibitor Representatives

Mike Torrance, Electro-Optics Technology, Inc., USA

Jeff Nichols, Pennwell, USA

\section{Ex-Officio}

Ann Catrina Bryce, Univ. of Glasgow, UK

Hui Cao, Yale Univ., USA

Timothy J. Carrig, Lockheed Martin Coherent Technologies, USA

Robert Fisher, R. A. Fisher Associates, USA

Claire F. Gmachl, Princeton Univ., USA

Ingmar Hartl, IMRA America, Inc., USA

Jacob B. Khurgin, Johns Hopkins Univ., USA

Paul D. Lett, NIST, USA

Hideo Mabuchi, Stanford Univ., USA

Harold J. Metcalf, SUNY Stony Brook, USA

Kaoru Minoshima, Natl. Inst. of Advanced Industrial Science \& Technology, Japan

Vladimir M. Shalaev, Purdue Univ., USA

Aephraim M. Steinberg, Univ. of Toronto, Canada

Konstantin L. Vodopyanov, Stanford Univ., USA

Hailin Wang, Univ. of Oregon, USA

Wegener Martin, Univ. Karlsruhe, Germany

Keith J. Williams, NRL, USA 


\section{Exhibitor Advisory Committee}

Mike Torrance, Electro-Optics Technology, Inc., USA, Chair and Exhibitor Representative to Steering Committee

Jeff Nichols, Pennwell, USA, Co-chair and Exhibitor Representative to Steering Committee Richard Bailey, UltraVolt, Inc., USA

Alain Bourdon, Allied Laser Solutions, USA

Amy Eskilson, Thorlabs, USA

Warren Gutheil, TecOptics, USA

Julia Otto, Coherent, Inc., USA

Fred Perry, Boston Electronics Corporation, USA

Rick Plympton, Optimax Systems, Inc., USA

Thomas Ruchti, Time-Bandwidth Products, Inc., Switzerland

Joachim R. Sacher, Sacher Lasertechnik GmbH, Germany

Mark Tolbert, Toptica, USA

Randall Wilcox, Lightspeed Technologies, USA

Don Wilson, Innovation Photonics, USA

\section{Joint Council on Quantum Electronics}

\section{APS/Division of Laser Science}

Michael G. Raymer, Univ. of Oregon, USA, Chair

Robert Boyd, Univ. of Rochester, USA

Wendell T. Hill, Univ. of Maryland at College Park, USA

\section{IEEE/Photonics Society}

Keren Bergman, Columbia Univ., USA

Alexander L. Gaeta, Cornell Univ., USA

David Hutchings, Univ. of Glasgow, UK

Optical Society of America

Steven Cundiff, NIST, USA

Prem Kumar, Northwestern Univ., USA

Antoinette Taylor, Los Alamos Natl. Lab, USA

\section{Invited Speakers}

\section{CLEO 01. Laser Processing of Materials: Fundamentals and Applications}

Tutorial Speaker

CMR1, Nanostructuring: A Route for Understanding Interaction Phenomena and Enhancing Materials Performance, Carmen N. Afonso; Laser Processing Group, Inst. de Optica, CSIC, Spain. 
CMLL1, Micro- and Nano- Scale System Manufacturing Using Ultrafast Lasers, Yves Bellouard; Technische Univ. Eindhoven, Netherlands

JTuA1, High Resolution 3-D Laser Direct-Write Patterning, Linjie Li, Rafael R. Gattass, Michael Stocker, Erez Gershgoren, Hana Hwang, John T. Fourkas; Univ. of Maryland, USA

\section{CLEO 02. Solid-State, Liquid and Gas Lasers}

Tutorial Speaker

CTuQQ1, Solid-State Laser Power Scaling to $100 \mathrm{~kW}$ and Beyond, Hagop Injeyan; Northrop Grumman Corp, USA

Invited Speakers

CTuFF1, Soft X-Ray Laser Pumped by a Joule-Class, All-Diode-Pumped Laser System, Brendan A. Reagan, Federico J. Furch, Bradley M. Luther, Alden H. Curtis, Shaun P. Meehan, Jorge J. Rocca; Colorado State Univ., USA

CTuJ1, Diamond Raman Lasers, Richard P. Mildren, A. Sabella, E. Granados, D. J. Spence; MQ Photonics Res. Ctr., Macquarie Univ., Australia

JThH2, Textron's J-HPSSL 100 kW ThinZag® Laser Program, Alex Mandl, Daniel E. Klimek; Textron Defense Systems, USA

\section{CLEO 03. Semiconductor Lasers}

CThM1, Technology, Manufacturing and Applications Associated with the Commercialization of Systems Based on Quantum Cascade Gain Media and Lasers, Tim Day; Daylight Solutions, USA

Invited Speakers

CME1, Recent Progress on High-Speed and Tunable VCSELs in the 1.3 to $2.6 \mu \mathrm{m}$ Wavelength Range, Markus Amann; Walter Schottky Inst., Technische Univ. München, Germany

CMII1, Reconfigurable, Multi-Section Quantum Dot Mode-Locked Lasers, Luke F. Lester, C.-Y. Lin, Y. Li, J. H. Kim, C. G. Christodoulou; Univ. of New Mexico, USA

CTuE1, Short Wavelength InP Based Quantum Cascade Lasers, Dmitry G. Revin ${ }^{1}$, James P. Commin $^{1}$, John W. Cockburn ${ }^{1}$, Shiyong Y. Zhang ${ }^{2}$, Kenneth Kennedy ${ }^{2}$, Andrey B. Krysa ${ }^{2}$, Mark Hopkinson ${ }^{2}$; ${ }^{1}$ Dept. of Physics and Astronomy, Univ. of Sheffield, UK, ${ }^{2}$ EPSRC Natl. Ctr. for IIIVTechnologies, Univ. of Sheffield, UK 
CTuO3, On-Chip Beam-Steering Photonic-Crystal Lasers, Yoshitaka Kurosaka ${ }^{1}$, Seita Iwahashi, ${ }^{1}$ Yong Liang ${ }^{1}$, Kyosuke Sakai ${ }^{12}$, Eiji Miyai ${ }^{1}$, Wataru Kunishi ${ }^{1,3}$, Dai Ohnishi ${ }^{1,3}$, Susumu Noda ${ }^{1}$; Dept. of Electronic Science and Engineering, Kyoto Univ., Japan, ${ }^{2}$ Kyoto Univ.

Pioneering Res. Unit for Next Generation, Kyoto Univ., Japan, ${ }^{3}$ Photonics Res. and

Development Ctr., ROHM Co., Ltd., Japan

CThU1, Operation of a 1.8-THz Quantum-Cascade Laser Above 160 K, Sushil Kumar', Chun W. I. Chan', Qing Hu ${ }^{1}$, John L. Reno ${ }^{2}{ }^{1}$ MIT, USA, ${ }^{2}$ Sandia Natl. Labs, USA

\section{CLEO 04. Applications of Nonlinear Optics}

\section{Tutorial Speaker}

CMCC1, Historical Perspective on Nonlinear Optics and Its Applications, $Y$. Ron Shen; Univ. of California at Berkeley, USA

Invited Speakers

CTuT3, Highly Efficient, Broadband Cherenkov Radiation in Photonic Crystal Fibers, $L i$ Jin Chen, Guoqing Chang, Franz X. Kärtner; MIT, USA

CWH3, Ultra-Broadband Optical Parametric Chirped-Pulse Amplifier Based on Aperiodically Poled Mg:LiNbO3 in the Mid-Infrared, Clemens Heese ${ }^{1}$, Lukas Gallmann ${ }^{1}$, Ursula Kellerl, Christopher Richard Phillips ${ }^{2}$, Martin Fejer'; ' ${ }^{2}$ TH Zurich, Switzerland, ${ }^{2}$ Stanford Univ., USA

CThP1, Optical Parametric Oscillators: A New Generation, Majid Ebrahim-Zadeh; ICFO, Inst. of Photonic Sciences, Spain

CFG1, Intrinsic Laser-Induced Damage in Bulk Transparent Dielectrics, Oleg M. Efimov; HRL Labs, LLC, USA

CFN3, Advances in Fiber-optic Parametric Amplifiers, John Harvey, S. G. Murdoch, R. Leonhardt; Univ. of Auckland, New Zealand

\section{CLEO 05. Terahertz Technologies and Applications}

Tutorial Speaker

CWF1, Recent Progress on Terahertz Quantum-Cascade Lasers, Sushil Kumar; MIT, USA Invited Speakers

CMF3, Single-Photon Detection in THz and Its Application, Susumu Komiyama; Univ. of Tokyo, Japan

CMP1, Mechanism and Potential Applications of THz Air Photonics, Jianming Dai, Jingle 
Liu, I-Chen Ho, Nicholas Karpowicz, X. C. Zhang; Rensselaer Polytechnic Inst., USA

CTuBB1, Nonlinear THz Spectroscopy on the Dielectric Thin Films, Ikufumi Katayama ${ }^{1}$ Hiroshi Aoki ${ }^{1}$, Jun Takeda ${ }^{1}$, Hiroshi Shimosato ${ }^{2}$, Masaaki Ashida $^{2}{ }^{3}$, Ryuhei Kinjo ${ }^{2}$, Iwao

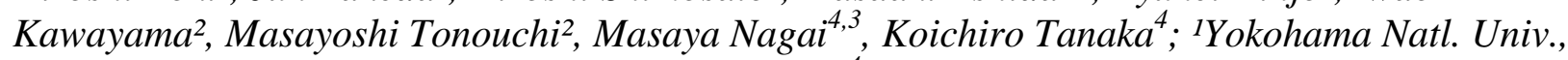
Japan, ${ }^{2}$ Osaka Univ., Japan, ${ }^{3}$ PRESTO JST, Japan, ${ }^{4}$ Kyoto Univ., Japan

CTuMM3, Quantum Cascade Laser Oscillating in Circuit-Based Resonator, Christoph Walther, Giacomo Scalari, Maria Amanti, Mattias Beck, Jérôme Faist; ETH Zurich, Switzerland

\section{CLEO 06. Optical Materials, Fabrication and Characterization}

CFF1, Three-Dimensional Optical Metamaterials and Nanoantennas: Chirality, Coupling, and Sensing, Harald Giessen, Na Liu; Univ. of Stuttgart, Germany

Invited Speakers

CMG1, QPM Wavelength Conversion Using Engineered LiNbO3 Waveguides, $M$. Asobe, $T$. Umeki, O. Tadanaga, H. B. Song, I. Tomita, K. Magari; NTT Photonics Labs, NTT Corp., Japan

CTuG1, New Frontiers of Organic Electro-Optic Materials and Devices: From Molecular Engineering to Technological Innovations, Alex Jen; Univ. of Washington, USA

CThL1, Novel Growth and Device Concepts for High-Efficiency InGaN Quantum Wells Light-Emitting Diodes, Hongping Zhao, Guangyu Liu, Xiao-Hang Li, Yik-Khoon Ee, Hua Tong, Jing Zhang, G. S. Huang, Nelson Tansu; Lehigh Univ., USA

\section{CLEO/QELS 07. Joint Subcommittee on High-Field Physics and High-Intensity Lasers}

Tutorial Speaker

JWC1, High Energy Density Science, Todd Ditmire; Univ. of Texas at Austin, USA

Invited Speakers

JThG1, The National Ignition Campaign on NIF, Brian MacGowan; Lawrence Livermore Natl. Lab, USA

JThI3, Full Phase Matching of Ultrafast Coherent High Harmonic X-Rays at 0.5 keV, Ming-Chang Chen, Paul Arpin, Tenio Popmintchev, Michael Ryan Gerrity, Matt Seaberg, Bosheng Zhang, Margaret Murnane, Henry Kapteyn; JILA, Univ. of Colorado at Boulder and NIST, USA

JFA1, Scientific Highlights from Operation of FLASH and New Opportunities with LCLS, Jochen Schneider; Deutsches Elektronen-Synchrotron DESY, Germany 


\section{CLEO 08. Ultrafast Optics, Optoelectronics and Applications}

CMEE1, Ultrafast Pulse Shaping and Applications, Andrew Weiner; Purdue Univ., USA

Invited Speakers

CTuGG1, Fiber-Based, Soliton-Tuned Femtosecond Optical Source Mid Infrared Spectral Region, Randy Bartels, David Winters, Greg Futia, Philip Schlup; Colorado State Univ., USA

CWJ1, Single-Cycle Light Pulses from a Compact Er:Fiber Laser, Günther Krauss, Tobias Hanke, Alexander Sell, Stefan Eggert, Rupert Huber, Alfred Leitenstorfer; Univ. of Konstanz, Germany

CThA1, High-Energy Femtosecond Fiber Lasers Based on Dissipative Solitons, Frank Wise; Cornell Univ., USA

CThQ1, High-Harmonic Generation by Resonant Plasmon Field Enhancement, Seung-Woo Kim, Seungchul Kim, In-Yong Park, Joonhee Choi; KAIST, Republic of Korea

CThQ3, Demonstration of Fully Spatially Coherent Soft X-Ray High Harmonic Beams in the Water Window, Paul C. Arpin ${ }^{1}$, Ming-Chang Chen ${ }^{1}$, Tenio Popmintchev ${ }^{1}$, Michael Gerrity ${ }^{1}$, Matt Seaberg', Bosheng Zhang ${ }^{1}$,Eric Gullikson', Farhad Salmassi², Yanwei Liu', Alon Bahabad', Henry C. Kapteyn', Margaret M. Murnane', ' IJILA, Univ. of Colorado at Boulder, USA, ${ }^{2}$ Ctr. for X-Ray Optics, Lawrence Berkeley Natl. Lab, USA

\section{CLEO 09. Components, Integration, Interconnects and Signal Processing}

Tutorial Speaker

CThF1, Microwave Photonics, Alwyn J. Seeds, Chin-Pang Liu, Tabassam Ismail, Martyn J. Fice, Francesca Pozzi, Robert J. Steed, Efthymios Rouvalis, Cyril C. Renaud; Univ. College London, $U K$

Invited Speakers

CWG5, Cavity Enhanced On-chip Spectrometer with Sub-nm Resolution, Bernardo B. C. Kyotoku ${ }^{12}$, Long Chen ${ }^{1}$, Michal Lipson ${ }^{1} ;{ }^{1}$ Cornell Univ., USA, ${ }^{2}$ Univ. Federal de Pernambuco, Brazil

CWP1, Integration of Nano-Photonic Devices for CMOS Chip-to-Chip Optical I/O, Ian Young, Bruce Block, Miriam Reshotko, Peter Chang; Intel Corp., USA

CFE3, Photonic Integrated Circuits for High-Speed Communications, Chris R. Doerr; Bell Labs, Alcatel-Lucent, USA 


\title{
CLEO 10. Biophotonics and Optofluidics
}

\author{
Tutorial Speaker
}

CThCC1, Single-Molecule Approaches for Superresolution Imaging, Trapping, and Nanophotonics, W. E. Moerner; Stanford Univ., USA

Invited Speakers

CTuY1, Tuning Mechanisms in Optofluidics, Demetri Psaltis, Wuzhou Song, Jae-Woo Choi; École Polytechnique Fédérale de Lausanne, Switzerland

CWD3, Label-Free Nonlinear Optical Imaging for Biology and Medicine, Sunney Xie; Harvard Univ., USA

\section{CLEO 11. Fiber Amplifiers, Lasers and Devices}

\section{Tutorial Speaker}

CTuC1, Recent Progress and Limiting Factors in High Power Fiber Laser Technology, Johan Nilsson; Univ. of Southampton, UK

Invited Speakers

CMM5, Bismuth-Doped Fiber Amplifiers, Evgeny M. Dianov, Igor A. Bufetov; Fiber Optics Res. Ctr., Russian Acad. of Sciences, Russian Federation

CMGG1, Photo Darkening of Ytterbium Fiber Lasers and Amplifiers, Kent E. Mattsson; Crystal Fibre, Denmark

CTuII3, Carbon Nanotube Photonics, Shinji Yamashita, Amos Martinez, Kin Kee Chow; Univ. of Tokyo, Japan

CTuM3, High Power 55 Watts CW Raman Fiber-Gas-Laser, Francois Couny ${ }^{1}$, Brian J. Mangan', Alexei V. Sokolov ${ }^{2}$, Fetah Benabid'; ${ }^{1}$ Ctr. for Photonics and Photonic Materials, Univ. of Bath, UK, ${ }^{2}$ Inst. for Quantum Studies and Dept. of Physics, Texas A\&M Univ., USA CWL1, Measuring the Modes of Optical Fibers Using S2 Imaging, Jeffrey W. Nicholson, John M. Fini, Samir Ghalmi, Jayesh C. Jasapara, Anthony DeSantolo, Eric Monberg, Frank Dimarcello; OFS Labs, USA

\section{CLEO 12. Lightwave Communications and Optical Networks}


CThDD1, Forward Error Correction (FEC) in Optical Communication, Frank Kschischang, Benjamin P. Smith; Univ. of Toronto, Canada

\section{Invited Speakers}

CFC3, Secure Optical Communications, Gregory Kanter; NuCrypt, LLC., USA

CFJ1, Multi-Granularity Waveband- and Wavelength Path Network, Ken-ichi Sato;

Nagoya Univ., Japan

CFJ2, $1.16 \mu$ s Continuously Tunable Optical Delay of a 100-Gb/s DQPSK Signal Using Wavelength Conversion and Chromatic Dispersion in an HNLF, Scott $R$. Nuccio, Omer F. Yilmaz, Xue Wang, Jian Wang, Xiaoxia Wu, Alan E. Willner; Univ. of Southern California, USA

\section{CLEO 13. Active Optical Sensing}

\section{Tutorial Speaker}

CMT1, Recent Advances in Cavity Ringdown Spectroscopy and Application to Medical Breath Analysis, Christopher S. Wood; Precision Photonics Corp., USA

\section{Invited Speakers}

CMJ1, Supercontinuum Radiation for Optical Sensing, Clemens Kaminski, Johan Hult, Toni Laurila; Univ. of Cambridge, UK

CTuB3, Photofragmentation Approaches for the Detection of Polyatomic Molecules, Thomas A. Reichardt, Alexandra A. Hoops, Jeffrey M. Headrick, Roger L. Farrow, Thomas B. Settersten, Scott E. Bisson, Thomas J. Kulp; Sandia Natl. Labs, USA

\section{CLEO 14. Optical Metrology}

Tutorial Speaker

CMD3, Optical Lattice Clocks toward 10-17 Uncertainty, Hidetoshi Katori; Univ. of Tokyo, Japan

Invited Speakers

CMN1, 75 W Yb-Fiber Laser Frequency Comb, Axel Ruehl, A. Marcinkevicius, M. E. Fermann, I. Hartl; IMRA America, Inc., USA

CTuDD5, Ultra-Low Noise Microwave Generation Using Femtosecond Lasers and Applications, Y. Le Coq ${ }^{1}$, J. Millo' , W. ZhangI, M. Abgrall', M. Lours ${ }^{1}$, H. Jiang ${ }^{1}$, E. M. L. English $^{1}$, R. Boudot ${ }^{2}$, P. Y. Bourgeois ${ }^{2}$, M. E. Tobar3, J. Guena', A. Clairon', A. Bize ${ }^{1}$, A. N. Luiten3, Y. Kersale3, G. Santarelli'; ' ${ }^{1}$ LNE-SYRTE, Observatoire de Paris, France, ${ }^{2} F E M T O-S T$ Inst., CNRS and ENSMM, France, ${ }^{3}$ School of Physics, Univ. of Western Australia, Australia 
CTuOO3, Ultrastable Atomic Force Microscopy Using Laser-Based, Active Noise Cancellation, Thomas T. Perkins, Gavin M. King, Allison B. Churnside, Ashley R. Carter; JILA, NIST and Univ. of Colorado at Boulder, USA

JWB1, Linearization of Ultra-broadband Optical Chirps for Precision Length Metrology, Zeb W. Barber ${ }^{1}$, Christoffer J. Renner ${ }^{1}$, Wm. Randall Babbitt ${ }^{1}$, Randy R. Reibel ${ }^{2}$, Peter A. Roos ${ }^{2}$, Trenton Berg ${ }^{2}$, Brant Kaylor ${ }^{2}$, Nathan Greenfield ${ }^{2}{ }^{1}$ Montana State Univ., USA, ${ }^{2}$ Bridger Photonics, USA

\section{CLEO 15. LEDS, Photovoltaics and Energy-Efficient (-Green\|) Photonics}

Tutorial Speaker

CTuCC1, III-Nitride UV Emitters and Their Applications, Asif Khan; Univ. of South Carolina, USA

Invited Speakers

CMAA1, Thin Film Silicon Solar Cell Fabricated at $100^{\circ} \mathrm{C}$ by High Density Plasma for Flexible Photovoltaic Application, Chang-Hong Shen ${ }^{1}$, Jia-Min Shieh ${ }^{1,2}$, Hao-Chung Kuo ${ }^{2}$, Jung Y. Huang ${ }^{2}$, Wen-Chien Yu ${ }^{1}$, Wen-Hsien Huang ${ }^{1}$, Chao-Kei Wang ${ }^{1}$, Chih-Wei Hsu' ${ }^{2}$ Yu-Hsin Lin', Hung-Yu Chiu' ${ }^{2}$, Bau-Tong Dail, Fu-Liang Yang' ${ }^{1}{ }^{1}$ Natl. Nano Device Labs, Taiwan, ${ }^{2}$ Inst. of Electro-Optical Engineering, Natl. Chiao Tung Univ., Taiwan

CMKK1, Efficiency Droop in GaInN Solid-State Lighting Devices, E. Fred Schubert, Martin F. Schubert; Rensselaer Polytechnic Inst., USA

\section{CLEO 16. Micro- and Nano-Photonics Devices}

\section{Tutorial Speaker}

CTuH1, Photonic Band Gap Materials: Light Control at Will, Sajeev John; Univ. of Toronto, Canada.

Invited Speakers

CMV1, Ultrafast Graphene Photodetector, Fengnian Xia ${ }^{1}$, Thomas Mueller ${ }^{2}$, Yu-ming Lin ${ }^{1}$, Phaedon Avouris ${ }^{1}$; IBM TJ Watson Res., USA, ${ }^{2}$ Vienna Univ. of Technology, Austria

CWB1, Photonic Crystal Nanobeam Cavities and Their Applications, Marko Loncar, P. B. Deotare, I. W. Frank, Y. Zhang, A. Conwill, M. Khan, M. W. McCutcheon, Q. Quan; Harvard Univ., USA

CWK1, Low-Power and High-Speed Operation of InGaAsP/InP Photonic Crystal Nanocavity Laser Using Wavelength-Sized Buried Heterostructure, Akihiko Shinyal, Shinji Matsuo $^{2}$, Takaaki Kakitsuka², Kengo Nozaki ${ }^{1}$, Toru Segawa ${ }^{2}$,Tomonari Sato ${ }^{2}$, Yoshihiro Kawaguch', Masaya Notomi'; ' ${ }^{2}$ TT Basic Res. Labs, Japan, ${ }^{2}$ NTT Photonics Labs, Japan 
CThJ1, Broadband Silicon Photonic Switch Integrated with CMOS Drive Electronics, Benjamin G. Lee, Joris Van Campenhout, Alexander V. Rylyakov, Clint L. Schow, William M. J. Green, Solomon Assefa, Min Yang, Fuad E. Doany, Christopher V. Jahnes, Richard A. John, Jeffrey A. Kash, Yurii A. Vlas; IBM Res., USA

CThR1, Ultrafast Silicon-Organic Hybrid (SOH) Photonics, Wolfgang Freude', Thomas Vallaitis $^{1}$, Christian Koos ${ }^{2}$; Jan-Michael Brosi ${ }^{3}$,Luca Alloatti', Pieter Dumon ${ }^{4}$, Roel Baets ${ }^{4}$, Michelle L. Scimeca ${ }^{5}$, Ivan Biaggio ${ }^{5}$, Benjamin Breiten ${ }^{6}$, François Diederich $^{6}$, Juerg Leuthold $^{1}$; ${ }^{1}$ Karlsruhe Inst. of Technology (KIT), Inst. of Photonics and Quantum Electronics (IPQ), Germany, ${ }^{2}$ Carl Zeiss AG, Germany, ${ }^{3}$ Robert Bosch GmbH, Power Tools Div., Germany, ${ }^{4}$ Ghent Univ., Photonics Res. Group, IMEC, Belgium, ${ }^{5}$ Lehigh Univ., Dept. of Physics, USA, ${ }^{6}$ ETH Zürich, Lab of Organic Chemistry, Switzerland

CFI1, Optical Metamaterials, Xiang Zhang; Univ. of California at Berkeley, USA

\section{QELS 01. Quantum Optics of Atoms, Molecules and Solids}

Tutorial Speaker

QThA1, Quantum Teleportation and Quantum Information Processing, Akira Furusawa; Univ. of Tokyo, Japan.

Invited Speakers

QTuB3, Quantum-Opto-Mechanics in the Strong Coupling Regime, Simon Gröblacher ${ }^{12}$, Sebastian Hofer ${ }^{2}$, Michael Vanner ${ }^{2}$, Klemens Hammerer ${ }^{1,3}$, Markus Aspelmeyer ${ }^{2}$; ${ }^{1}$ Austrian Acad. of Sciences, Austria, ${ }^{2}$ Univ. of Vienna, Austria, ${ }^{3}$ Inst. for Theoretical Physics, Univ. of Innsbruck, Austria

QFE5, A Quantum Gas Microscope for Detecting Single Atoms in a Hubbard-Regime Optical Lattice, Markus Greiner; Harvard Univ., USA

\section{QELS 02. Quantum Science, Engineering and Technology}

Tutorial Speaker

QFF1, Measuring and Characterizing Quantum States and Processes, Daniel F. V. James; Univ. of Toronto, Canada

Invited Speakers

QThD1, Complete Characterization of Weak-Homodyne Photon-Number-Resolving Detectors: Applications to Non-Classical Photonic State Reconstructions, Hendrik B. Coldenstrodt-Ronge ${ }^{1}$, Graciana Puentes ${ }^{1}$, Offir Cohen ${ }^{1}$, Florencia Noriega ${ }^{1}$, Xiaodan Yang ${ }^{1}$, Jeff S. Lundeen ${ }^{2}$, Animesh Datta ${ }^{3}$, Lijian Zhang ${ }^{1}$, Brian J. Smith ${ }^{1,4}$, Martin B. Plenio ${ }^{5}$, Ian A. Walmsley'; ' ${ }^{1}$ Univ. of Oxford, UK, ${ }^{2}$ Inst. for Natl. Measurement Standards, Canada, ${ }^{3}$ Imperial College, UK, ${ }^{4}$ NUS Ctr. for Quantum Technologies, Singapore, ${ }^{5}$ Ulm Univ., Germany

QThG1, Advances in Photonic Quantum Information Science, Alberto Politi ${ }^{1}$, Jonathan C. F. Matthews ${ }^{1}$, Anthony Laing ${ }^{1}$, Alberto Peruzzo ${ }^{1}$, Pruet Kalasuwan ${ }^{1}$, Xiao-Qi Zhou ${ }^{1}$, Maria 
Rodas Verde ${ }^{1}$, Martin J. Cryan ${ }^{1}$, John G. Rarity ${ }^{1}$, Andre Stefanov ${ }^{2}$, Timothy C. Ralph ${ }^{3}$, Siyuan $Y u^{1}$, Mark G. Thompson ${ }^{1}$, Jeremy L. O'Brien ${ }^{1}$; ${ }^{1}$ Univ. of Bristol, UK, ${ }^{2}$ Federal Office of Metrology METAS, Switzerland, ${ }^{3}$ Univ. of Queensland, Australia

QThJ1, Suppression of Collisional Decoherence in Optically Trapped Atomic Ensemble by Bang-Bang Dynamical Decoupling, Yoav Sagi, Ido Almog, Nir Davidson; Weizmann Inst. of Science, Israel

QFA1, Squeezed Light for Gravitational Wave Detection, Roman Schnabel; Leibniz Univ. Hannover, Germany

\section{QELS 03. Metamaterials and Complex Media}

\section{Tutorial Speaker}

QThB1, Transforming Light with Tunable and Active Metamaterials, Vladimir M. Shalaev; Purdue Univ., USA

Invited Speakers

QMG1, Band Gaps in Amorphous Photonic Lattices, Mikael Rechtsman ${ }^{1}$, Alexander Szameit ${ }^{2}$, Felix Dreisow ${ }^{3}$, Matthias Heinrich ${ }^{3}$, Robert Keil ${ }^{3}$, Stefan Nolte ${ }^{3}$, Mordechai Segev²; ${ }^{1}$ Courant Inst. of Mathematical Sciences, New York Univ., USA, ${ }^{2}$ Physics Dept. and Solid State Inst., Technion-Israel Inst. of Technology, Israel, ${ }^{3}$ Inst. of Applied Physics, Friedrich Schiller Univ. Jena, Germany

QWF1, Photonic Metamaterials Go Three-Dimensional, Martin Wegener; Inst. für Angewandte Physik und Inst. für Nanotechnologie, Karlsruhe Inst. of Technology (KIT), Germany

QFH1, Physics and Applications of One-Way Magneto-Optical Photonic Crystals, Zheng Wang, Yidong Chong, John Joannopoulos, Marin Soljačić; MIT, USA

\section{QELS 04. Optical Interactions with Condensed Matter and Ultrafast Phenomena}

\section{Tutorial Speaker}

QThM1, Quantum Optics with Semiconductor Quantum Dots in Microcavities, C. Gies, S. Ritter, M. Florian, P. Gartner, Frank Jahnke; Inst. for Theoretical Physics, Univ. of Bremen, Germany

\section{Invited Speakers}

QWC1, Spin Hall Effect of Light in GaAs and Silicon Observed via Nonlinear Optics, JeanMichel Menard ${ }^{1}$, Adam E. Mattacchione ${ }^{1}$, Christine Hautmann ${ }^{2}$, Markus Betz ${ }^{2}$, Henry M. van Driel ${ }^{1} ;{ }^{1}$ Univ. of Toronto, Canada, ${ }^{2}$ Technische Univ. München, Germany 
Rudolf Bratschitsch; Univ. Konstanz, Germany

QThF5, Quantum Kinetics of Transport and Gain in Quantum Cascade Lasers: Looking for the Essential Principles of Design, Andreas Wacker; Lund Univ., Sweden

\section{QELS 05. Nonlinear Optics and Novel Phenomena}

\section{Tutorial Speaker}

QWA1, Filamentation of Femtosecond Laser Pulses: Basic Principles and Applications, André Mysyrowicz; Lab d'Optique Appliquée, France

\section{Invited Speakers}

QTuE5, Two Photon Emission, Entanglement and Gain from Semiconductors at Room Temperature, Meir Orenstein, Alex Hayat, Amir Nevet, Pavel Ginzburg, Serge Rosenblum; Technion Israel Inst. of Technology, Israel

QWE5, Highly Efficient Four Wave Mixing in InGaP Photonic Crystal Waveguides, Isabelle Cestier ${ }^{1}$, Vardit Eckhouse ${ }^{1}$, Gadi Eisenstein ${ }^{1}$, Sylvain Combrié2, Pierre Colman ${ }^{2}$, Alfredo De Rossi'; 'Technion, Israel, ${ }^{2}$ Thales Res. and Development, France

QFB1, Modulation of Photons and Biphotons, Steve Harris, C. Belthangady, Chih-Sung Chuu, S. Du, P. Kolchin, S. Sensarn, I. A. Yu, J. M. Kahn, G. Y. Yin; Ginzton Lab, Stanford Univ., USA

QFG1, Laser Cooling of a Semiconductor Load to 165 K, Denis V. Seletskiy, Seth D. Melgaard', Mansoor Sheik-Bahae', Stefano Bigotta ${ }^{2}$,Alberto Di Lieto ${ }^{2}$, Mauro Tonelli ${ }^{2}{ }^{1}{ }^{2}$ niv. of New Mexico, USA, ${ }^{2}$ Univ. di Pisa, Italy

\section{QELS 06. Nano-Optics and Plasmonics}

Tutorial Speaker

QMB1, New Concepts in Nanoplasmonics, Stefan Maier; Imperial College London, UK Invited Speakers

QMD3, Light-to-Current and Current-to-Light Coupling in Plasmonic System, Natalia Noginova, Andrey V. Yakim, Mikhail Noginov; Norfolk State Univ., USA

QMH3, Lithographically Fabricated Optical Antennas with Sub-10nm Gaps Formed by a Sacrifical Layer, Wenqi Zhu, Mohamad G. Banaee, Kenneth B. Crozier; Harvard Univ., USA 
QThH3, A Pointed Look at Light at the Nanoscale, L. (Kobus) Kuipers; FOM Inst. for Atomic and Molecular Physics, Netherlands

QFC1, Plasmonic Interference and Coherence in Metallic Nanostructures, Peter

Nordlander; Rice Univ., USA

\section{CLEO/QELS 07. Joint Subcommittee on High-Field Physics and High-Intensity Lasers}

Tutorial Speaker

JWC1, High Energy Density Science, Todd Ditmire; Univ. of Texas at Austin, USA

Invited Speakers

JThG1, The National Ignition Campaign on NIF, Brian MacGowan; Lawrence Livermore Natl. Lab, USA

JThI3, Full Phase Matching of Ultrafast Coherent High Harmonic X-Rays at $0.5 \mathrm{keV}$, Ming-Chang Chen, Paul Arpin, Tenio Popmintchev, Michael Ryan Gerrity, Matt Seaberg, Bosheng Zhang, Margaret Murnane, Henry Kapteyn; JILA, Univ. of Colorado at Boulder and NIST, USA

JFA1, Scientific Highlights from Operation of FLASH and New Opportunities with LCLS, Jochen Schneider; Deutsches Elektronen-Synchrotron DESY, Germany

Special Symposia

\section{CLEO Symposium on Laser Beam Combining: Sources and Applications}

\section{Symposium Organizers}

Richard Berdine; AF Res. Lab, KAFB; USA

Dan Yanson; Semi Conductor Devices Ltd., Israel

Daniel J. Ripin; MIT Lincoln Lab, USA

Beam combining methods that provide brightness scaling by combining the outputs of multiple lasers or amplifiers with high combined beam quality have made dramatic advances over the past few years. This symposium will bring together researchers exploring various incoherent (e.g. 
wavelength beam combining) and coherent (both active and passive) beam combining methods using solid-state, semiconductor (incl. VCSEL) and fiber laser and amplifier platforms and their use in industrial, military, pumping and communications applications. Contributions discussing the scaling of element count and combined powers (incl. sub- $\mathrm{kW}$ and multi-kW arrays), multilevel and integrated architectures, enabling technologies (phase detection and control algorithms, high power gratings), increasing beam-combinable power from individual elements, and beam characterization techniques are welcome.

Contributed submissions to CLEO 2, CLEO 3, and CLEO 11 will be considered for this symposium.

Tutorial Speaker

CThG1, Laser Beam Combining: Theory and Methods, James R. Leger; Univ. of Minnesota, $U S A$

Invited Speakers

CThG2, Coherent Beam Combining of Fiber Amplifiers and Solid-State Lasers including the use of Diffractive Optical Elements, Michael Wickham; Northrop Grumman Corp., USA

CThO1, Beam Combining in Multi-core, Holey Fiber Lasers, Terence Shepherd, Laurent Michaille, Charlotte R. Bennett, David M. Taylor; QinetiQ Ltd., UK

CThO3, Coherent Fiber Combining by Digital Holography, Cindy Bellanger ${ }^{1}$, M. Paurisse ${ }^{2}$,

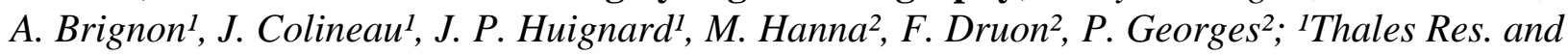
Technology, France, ${ }^{2}$ Lab Charles Fabry de l'Inst. d'Optique, Univ. Paris-Sud, France

CThX1, Volume Bragg Gratings for Spectral Beam Combining, Leonid B. Glebov ${ }^{1,2}$; ${ }^{1}$ CREOL, College of Optics and Photonics, Univ. of Central Florida, USA, ${ }^{2}$ OptiGrate Corp., USA

CThX2, Beam Reformatting and Combining of High-Power Laser Diode Stacks, Howard J. Baker ${ }^{1}$, N. Trela ${ }^{1}$, D. R. Hall ${ }^{1}$, R. McBride ${ }^{2}$, J. J. Wendland ${ }^{2}{ }^{1}$ Heriot-Watt Univ., UK, ${ }^{2}$ PowerPhotonic Ltd, UK

\section{CLEO Symposium on Photonics for Advanced Energy Technology}

\section{Symposium Organizers}

Michael Wraback; US ARL, USA

S. J. Ben Yoo; Univ. of California at Davis, USA

Leo Schowalter; Crystal IS, USA 
Photonic-based electrical power generation and energy-efficient photonics will play a key role in the reduction of the collective energy footprint that is fast becoming an important global priority. The goal of this symposium is to bring together researchers exploring all aspects of efficient photonic power generation and use, including novel materials, devices, and systems. Topics to be covered in this symposium include (but are not limited to) the physics, engineering, and applications of high-efficiency and flexible photovoltaics, high-efficiency LEDs and lasers, and energy-efficient photonic systems. The role of Photonics in energy-efficient computing, networking, and information systems will also be covered.

Contributed submissions to CLEO 15 will be considered for this symposium.

Invited Speakers

CMB1, Recent Progress in High Efficiency InGaN LEDs, Matthias Peter, Karl Engl, Frank Baumann, Ralph Wirth, Ansgar Laubsch, Johannes Baur, Berthold Hahn; OSRAM Opto

Semiconductors GmbH, Germany

CMB4, Energy Footprint and Opportunities of ICT Networks, Loukas Paraschis; Cisco Systems, USA

CML1, High-Efficiency Photovoltaic Technology, Sarah Kurtz; Natl. Renewable Energy Lab, USA

CML4, Photonic Power Delivery, Jan-Gustav Werthen; JDS Uniphase Corp., USA

\section{CLEO Symposium on Novel Optical Fibers for Sensing, Medicine, Spectroscopy, and Future Communication Systems}

\section{Symposium Organizers}

Jacques Albert; Carleton Univ., Canada

David DiGiovanni, OFS Labs, USA

Optical fiber technologies have evolved considerably in the last decade to best fit an expanding range of applications. This symposium is devoted to state-of-the-art optical fiber designs for various fields including bio-chemical and physical sensing, biomedical instrumentation, spectroscopy, as well as the optical communication systems of the future.

Within the realm of applications listed above, advanced materials and guiding geometries, new fabrication methods, and hybrid fibers with functional coatings, dopants or inclusions are covered by the symposium. 
The symposium will solicit speakers that are users of specialty optical fibers to present their views on the properties they wish fibers had. Fiber designers will be invited to present advanced fiber designs and describe the challenges associated to creating fibers with specific properties. A perspective on the future of fibers in the next 10 and 20 years will also be presented.

Contributed submissions to CLEO 10, CLEO 11, CLEO 12, and CLEO 13 will be considered for this symposium.

Invited Speakers

CTuP1, The Influence of Optical Fiber Design on Chemical Sensor Performance, Robert Lieberman; Intelligent Optical Systems, Inc., USA

CTuP4, Holographically Encoded Microparticles: A Flexible Multiplex Platform for Bioassay Applications, J. A. Moon, M. S. Bowen, J. F. Pinto; Illumina, Inc., USA

CTuAA1, Fibers for Next-Generation High Spectral Efficiency Undersea Cable Systems, Neal S. Bergano, Alexei Pilipetskii; Tyco Telecommunications, USA

CTuAA4, Advanced Optical Fibers for Geophysical Sensing Applications, Paul E. Sanders; Qorex, USA

CTuLL1, Integration of Semiconductors, Molecules, and Metals into Microstructured Optical Fibers, John V. Badding ${ }^{1}$, N. F. Baril', J. R. Sparks ${ }^{1}$, J. A. Calkins ${ }^{1}$, D. A. Allara ${ }^{1}$, P. J. A. Sazio ${ }^{2}$, A. C. Peacock ${ }^{2}$, N. Healy², V. Gopalan', M. Krishnamurthy', I. Temnykh ${ }^{1}$;

${ }^{1}$ Pennsylvania State Univ., USA, ${ }^{2}$ Optoelectronics Res. Ctr., Univ. of Southampton, UK.

CTuLL4, Design and Fabrication of Photonic Crystal Fibers for Plasmonic Sensing, Applications from the Visible to THz, Maksim Skorobogatiy; École Polytechnique de Montréal, Canada

\section{QELS Symposium on Quantum Repeaters and Networks}

\section{Symposium Organizers}

Christoph Simon; Univ. of Calgary, Canada

Perry Rice; Miami Univ., USA

Norbert Lütkenhaus; Univ. of Waterloo, Canada

The distribution of entanglement over long distances is an important challenge both from a fundamental point of view and for applications such as quantum cryptography or a future potential "quantum internet". The direct distribution of entanglement is limited by unavoidable transmission losses in combination with the no-cloning theorem for quantum states. This limitation can be overcome through quantum repeaters, which are based on creating entanglement for relatively short elementary links, storing it in quantum memories, and then 
extending it through entanglement swapping. The last few years have seen significant experimental and theoretical progress in the area of quantum repeaters and quantum networks. On the experimental side, elementary links of quantum repeaters have been demonstrated in several systems, including atomic ensembles and trapped ions. Quantum memories based on atomic ensembles, both in atomic gases and in the solid state, are becoming ever more efficient, and storage times are increasing. At the same time, improved protocols are being developed on the theory side. This symposium aims to give an overview over these exciting developments.

Contributed submissions to QELS 1 and QELS 2 will be considered for this symposium.

Invited Speakers

QWD1, Quantum Optical Networks with Trapped Ions, Christopher Monroe; Univ. of Maryland and Joint Quantum Inst., USA

QWD2, Quantum Networks with Single Atoms, Photons and Phonons, H. Jeff Kimble; Caltech, USA

QWH1, Experimental Manipulation of Atoms and Photons and Its Applications, Jianwei Pan; Univ. Heidelberg, Germany

QWH2, Solid State Quantum Memories for Quantum Repeaters, Hugues de Riedmatten ${ }^{1}$, I. Usmani ${ }^{1}$, B. Lauritzen 1 , C. Clausen ${ }^{1}$, J. Minářrl, N. Sangouard ${ }^{1}$, C. Simon ${ }^{12}$, A. Amari ${ }^{3}$, A. Walther ${ }^{3}$, S. Kröll ${ }^{3}$, M. Afzelius ${ }^{1}$, N. Gisin ${ }^{1}$; ${ }^{1}$ Univ. of Geneva, Switzerland, ${ }^{2}$ Univ. of Calgary, Canada, ${ }^{3}$ Dept. of Physics, Lund Inst. of Technology, Sweden

\section{QELS Symposium on Nanophotonics and Metamaterials}

\section{Symposium Organizers}

Vladimir Shalaev; Purdue Univ., USA

Nikolay Zheludev; Univ. of Southampton, UK

It is a daunting challenge to bring photonics to the nanometer scale because of the fundamental diffraction limit. Metamaterials (MMs), i.e. artificial materials with rationally designed geometry, composition and arrangement of nanostructured building blocks, or meta-"atoms," can enable the needed compatibility between light with a wavelength at the microscale and optoelectronic systems operating at the nanoscale. Thus MMs can combine the advantages of the $\mathrm{nm}$-scale (but relatively slow) electronics and ultra-fast (but $\mu \mathrm{m}$-scale) photonics, bridging the size gap and enabling an increased synergy between the two major technologies. The research themes of this Symposium are aimed at understanding, controlling and utilizing the fundamental physical phenomena occurring in MMs for addressing the grand challenge and societal need for faster, smaller and more efficient optical and opto-electronic systems.

Contributed submissions to QELS 3 and QELS 6 will be considered for this symposium. 
Invited Speakers

QTuD1, Infinite at Every Frequency: The Photonic Density of States in (Meta)materials with Hyperbolic Dispersion and Related Phenomena, Evgenii Narimanov, Zubin Jacob, Igor Smolyaninov; Purdue Univ., USA

QTuF1, Reconstruction of Sparse Sub-Wavelength Images, Alexander Szameit, Snir Gazit, Yonina C. Eldar, Mordechai Segev; Technion-Israel Inst. of Technology, Israel

QTuF5, Nanodevices Based on Plasmonics for Few/Single Molecule Detection, Enzo Di Fabrizio; Italian Inst. of Technology, Italy

QTuH1, Nonlinear Wave Control and Rainbows in Complex Gyroelectric Structures, Allan D. Boardman ${ }^{1}$, Peter Egan ${ }^{1}$, Ortwin Hess ${ }^{2}$, Rhiannon C. Mitchell-Thomas ${ }^{1}$, Yuriy G. Rapoport ${ }^{1}$; ${ }^{1}$ Univ. of Salford, UK, ${ }^{2}$ Univ. of Surrey, UK, ${ }^{3}$ Taras Shevchenko Kyiv Natl. Univ., Ukraine

\section{Joint CLEO/QELS Symposium on Quantum Control}

\section{Symposium Organizers}

Marcos Dantus; Michigan State University, USA

Andrew Doherty; Univ. of Queensland, Australia

Recent years have seen an explosion in experimental capabilities for the manipulation and control of both light and matter. For example, ultrafast lasers now provide extraordinarily high peak intensities and allow interaction and control of matter on a timescale that is faster than atomic motion. By modulating the spectral phase, polarization and amplitude of ultrafast pulses, computer controlled pulse shapers allow the creation of arbitrary pulse shapes. This technology is being used to control electrons, atoms, molecules, nanoparticles and bulk media. In many other areas of AMO physics it is increasingly possible to achieve high signal-to-noise for measurements on individual atoms or photons in real time and to feed back to control dynamics of individual quantum systems. These experimental innovations have stimulated theoretical developments in what could be called quantum control theory, which systematically seeks to take advantage of these capabilities to achieve an unprecedented ability to manipulate individual quantum systems. This work has seen the application of existing techniques from NMR and from control theory and opens very exciting avenues for experimental research into the fundamentals of quantum physics. Moreover, while this research field is still in its infancy, a number of very promising applications are also being developed and some have already been commercialized.

This symposium will review key conceptual and technological developments and discuss emerging, interdisciplinary research into photonic control of matter and nonlinear optical processes. This symposium will consist of invited and contributed papers.

Contributed submissions to CLEO 13, QELS 1, and QELS 2 will be considered for this symposium. 


\section{Invited Speakers}

JThC1, Preserving Quantum Coherence Using Optimized Open-Loop Control Techniques, Michael J. Biercuk, Hermann Uys, Aaron P. VanDevender, Nobuyasu Shiga, Wayne M. Itano, John J. Bollinger; NIST, USA

JThC4, Optical Arbitrary Waveform Generation, E. Ippen, A. Benedick, J. Birge, H. Byun, L.-J. Chen, G. Chang, D. Chao, J. Morse, A. Motamedi, M. Sander, G. Petrich, L. Kolodziejski, F. Kärtner; MIT, USA

JThF1, Femtosecond Spatiotemporal Control with Multiple Knobs, Debabrata Goswami; Indian Inst. of Technology, Kanpur, India

JThF2, From Order to Chaos with a Spin and a Twist, Poul S. Jessen ${ }^{1}$, I. H. Deutsch ${ }^{2}$, S. Ghose ${ }^{3}$ ' ${ }^{1}$ niv. of Arizona, USA, ${ }^{2}$ Univ. of New Mexico, USA, ${ }^{3}$ Wilfrid Laurier Univ., Canada

\section{Joint CLEO/QELS Symposium on Optomechanics for Physical and Biological}

\section{Sciences}

\section{Symposium Organizers}

Seok-Hyun Andy Yun; Harvard Univ., USA

Tobias Kippenberg; EPFL, Switzerland

The use of radiation pressure to probe and manipulate micromechanical systems has proven useful in diverse fields of science and engineering ranging from quantum dynamics to bioengineering. This symposium discusses the fundamentals, technology, and applications of optomechanics in topics including cavity optomechanics, micro- and nano-optomechanical devices, optical tweezers, and optical probing of cell and tissue biomechanics.

Contributed submissions to CLEO 6, CLEO 10, QELS 2, and QELS 6 will be considered for this symposium.

\section{Invited Speakers}

JMA1, Nonequilibrium Quantum Dynamics in Optomechanical Systems, Florian Marquardt; Ludwig-Maximilians-Univ. Munich, Germany

JMA2, Feasability of Measuring Radiation Pressure Quantum Back-Action in Zipper Photonic Crystal Optomechanical Cavities, Jeffrey T. Hill, Ryan Camacho, Alexander G. Krause, Oskar J. Painter; Caltech, USA

JMB1, The Physics of a Dissipative Optomechanical Coupling, Aashish Clerk; McGill Univ., Canada 
JMB4, Preparation and Detection of a Radio Frequency Mechanical Resonator Near the Ground State of Motion, Keith Schwab; Caltech, USA

JMC5, Sound, Light and Particles in Photonic Crystal Fibres, Philip Russell, A. Brenn, T. G. Euser, M. K. Garbos, M. S. Kang, A. Nazarkin; Max-Planck Inst. for the Science of Light, Germany

JMD1, Light Takes Shape for Biophotonics: New Directions in Trapping and Cell Transfection, Kishan Dholakia; Univ. of St. Andrews, UK

JMD4, Microrheology Measurements of the Mechanical Properties of Cells, David Weitz; Harvard Univ., USA

\section{Plenary Session and Awards}

Wedinesdlay, May 19, 2010

8:00 a.m.-10:30 a.m.

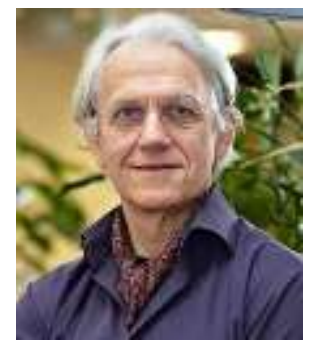

New Physics at Extreme Intensities of Light

Gérard Mourou

École Polytechnique, France

Biography: Gérard Mourou is a professor at the École Polytechnique and director of the Institut de la Lumière Extrême at ENSTA. He has made important contributions in the field of ultrafast lasers, high-speed electronics as well as ophthalmology.

However, his most important one is certainly the invention of the laser amplification technique universally used today known as Chirped Pulse Amplification (CPA).

CPA made possible the generation of extremely high laser intensities that opened a new branch of optics: relativistic optics, where laser-matter interaction is dominated by the relativistic character of the electrons. In this regime it is possible to make compact particle accelerators, or sources of coherent high energy radiation beams. Note also other applications such as thermonuclear fusion where the short and intense pulse is used as a fast igniter of the compressed fuel.

The field of relativistic optics is one of the most active fields of physics today. In 2005, Mourou proposed, with twelve European partners, a new infrastructure called ELI (Extreme Light Infrastructure). ELI will host the most intense laser in the world. It is on the road map of the large European Infrastructure facilities. At the University of Michigan, Mourou pioneered the 
field of femtosecond ophthalmology where the femtosecond laser is used to perform precise cut for myopia correction or corneal transplant.

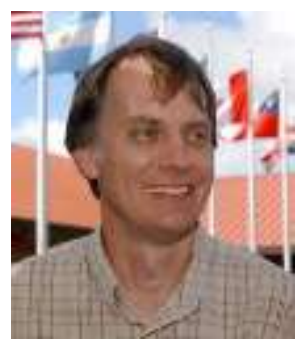

\author{
A New Portal on the Universe-Laser Adaptive Optics \\ Douglas Simons \\ Gemini Observatory, USA
}

\begin{abstract}
As we enter the 21st century, the legacy started by Galileo 400 years ago continues with a new generation of enormous telescopes equipped with advanced technologies including adaptive optics and laser beacons. The telescopes of the new
\end{abstract} century stand to transform our understanding of the cosmos and our place in it.

Biography: Douglas Simons' scientific interests include: infrared research on low mass stars, brown dwarfs, and the Galactic center. Past contributions to astronomy include leading the development of advanced infrared instrumentation at major observatories, which has been used for a variety of research applications by the astronomical community. These efforts have been at various levels ranging from technical design, to scientific leadership within the community, to management of diverse teams and resources around the world tasked with developing instrumentation for Gemini Observatory. Since 2006 he has served as the Director of Gemini Observatory which includes a pair of infrared optimized $8 \mathrm{~m}$ telescopes located on the summits of Mauna Kea in Hawaii and Cerro Pachon in Chile. These unique world class research facilities feature some of the most advanced electro-optic systems used in astronomy today, including high power sodium lasers and advanced high order adaptive optics systems.

\title{
Plenary Session and Awards
}

\section{Wednesdlay, May 19, 2010}

8:00 a.m.-10:30 a.m.

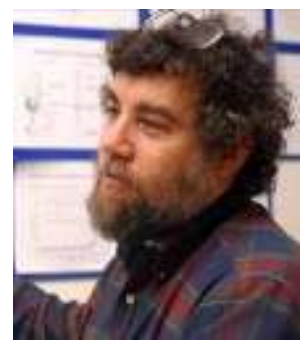

Single Molecule Biophysics with Optical Tweezers

Steven Block

Stanford Univ., USA

Abstract: Optical tweezers (optical traps) have enjoyed their greatest utility in the emerging field of single-molecule biophysics, where they're being used to study the nanoscale properties of individual biological macromolecules. This talk will discuss recent progress.

Biography: Steven M. Block is a professor at Stanford University with a joint appointment in the departments of biological sciences and applied physics. In addition, he is a member of the scientific advisory group JASON, a senior fellow of Stanford's Freeman Spogli Institute for International Studies, and an amateur bluegrass musician. 
Block received his BA and MA from Oxford University. He has been elected to the US National Academy of Sciences (2007) and the American Academy of Arts and Sciences (2000), and is a winner of the Max Delbruck Prize of the American Physical Society (2008), as well as the Single Molecule Biophysics Prize of the Biophysical Society (2007). He served as President of the Biophysical Society during 2005-2006. His graduate work was completed in the laboratory of Howard Berg at the University of Colorado and Caltech. He received his $\mathrm{PhD}$ in 1983 and went on to do postdoctoral research at Stanford. Since that time, Block held positions at the Rowland Institute for Science, Harvard University, and Princeton University before returning to Stanford in 1999.

Block has researched the many threats associated with bioterrorism and headed influential studies on how advances in genetic engineering have impacted biological warfare.

Work in his lab has led to the direct observation of the 8-m steps taken by kinesin and the demonstration that these steps consume as fuel only a single molecule of adenosine triphosphate (ATP), up to applied loads on the motor enzyme of several picoNewtons $(\mathrm{pN})$.

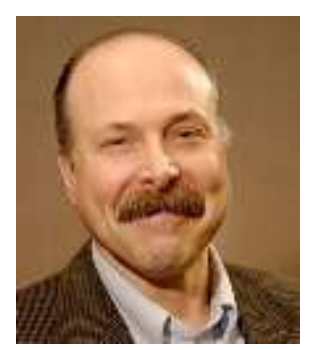

Manipulating Single Spins and Coherence in Semiconductors

David Awschalom

Univ. of California at Santa Barbara, USA

Abstract: Contemporary information technology relies on classical physics, utilizing electronic charge for computation and magnetic materials for storage. We describe recent optoelectronic experiments with single electron spins in diamond that may enable fundamentally different quantum-based information technologies.

Biography: David Awschalom obtained a BSc in physics from the University of Illinois at UrbanaChampaign, and a PhD in physics from Cornell University. After serving as a research staff member and manager of the nonequilibrium physics group at the IBM Watson Research Center, he joined the University of California-Santa Barbara as a professor of physics, electrical and computer engineering. He is presently the Peter J. Clarke Professor and director of the California NanoSystems Institute, and Director of the Center for Spintronics and Quantum Computation. His group has research activities in optical and magnetic interactions in semiconductor quantum structures, spin dynamics and coherence in condensed matter systems, and implementations of quantum information processing in the solid state. He has developed a variety of femtosecond-resolved spatiotemporal spectroscopies and micromagnetic sensing techniques aimed at exploring charge and spin motion in the quantum domain. Awschalom received an IBM Outstanding Innovation Award, the Outstanding Investigator Prize of the Materials Research Society, the International Magnetism Prize and Néel Medal of the International Union of Pure and Applied Physics, the Oliver E. Buckley Prize of the American Physical Society, the Europhysics Prize of the European Physical Society, and the Newcomb Cleveland Prize of the American Association for the Advancement of Science. Awschalom is a Fellow of the American Physical Society, the American Association for the Advancement of Science, the American Academy of Arts and Sciences, and a member of the National Academy of Sciences. 


\section{Market Focus}

Part of the CLEO: Applications program, Market Focus sessions cover business and commercialized applications and are held on the exhibit floor. Market Focus is free to all attendees.

\section{Market Focus Chairs}

Gail Overton; Laser Focus World, USA, CLEO Market Focus Chair Nick Traggis; Precision Photonics Corp., USA, CLEO Market Focus Co-Chair

\section{Market Focus Committee}

Dr. Tony Hoult, IPG Photonics, USA

Bill Kozlovsky, Skyline Solar, USA

Keshav Kumar, Newport Corp., USA

L. A. (Vern) Schlie, Integral Laser Solutions, USA

Eric Takeuchi, Daylight Solutions, USA

\section{Industrial Lasers}

High Energy Lasers for Industrial Uses, L. A. (Vern) Schlie, Independent Consultant, Integral Laser Solutions, LLC, USA, Moderator

High Energy Lasers, particularly the closed cycle gas and solid-state laser systems, are becoming increasingly attractive for industrial uses for both

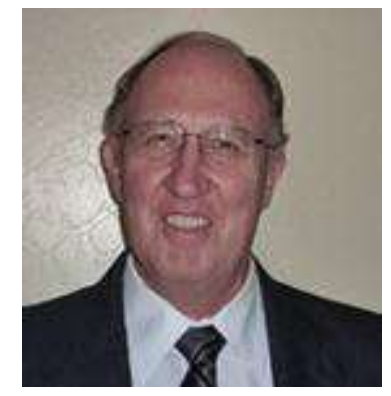
creation of new applications and enhancing present uses. In this session, presentations on fiber, thin disk, and bulk SSL plus closed cycle RF waveguide lasers will be presented. The talks will concentrate on the unique features of the HEL systems that open new uses, with emphasis on system compact packaging, efficiency, 24/7 operation, and present commercial sales. Also, the future needs and trends for these HEL systems will be discussed. Following the presentations, a round-table -question and answerll workshop will be conducted whereby the audience can question the six presenters on matter dealing with present \& expanded future uses of HEL industrial uses for the next decade, 20102020, throughout the world.

\section{Speakers:}

Industrial Perspectives of Ultrafast High Energy and High Average Power Fiber Lasers, Prof. Andreas. Tünnermann, Director, Fraunhofer Inst. for Applied Optics and Precision Engineering, Germany

In the past years rare-earth-doped fiber lasers have emerged as attractive and power scalable solid-state laser concept due to the outstanding thermo-

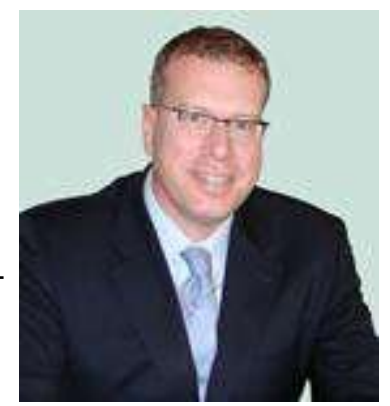


optical properties of an actively doped fiber. The large ratio of surface to active volume of such a fiber ensures excellent heat dissipation, furthermore the beam quality is defined by the refractive index profile of the active core and is therefore independent on the pump power. Fiber lasers and amplifiers offer a very high single-pass gain and therefore low laser thresholds and efficient diode-pumped operation.

Using advanced fiber designs, in continuous-wave operation output powers exceeding the multi$\mathrm{kW}$-level with diffraction-limited beam quality have been demonstrated. In the pulsed regime average powers in the order of several hundred Watt have been reported. However, power and energy scaling of ultrafast single-mode fiber amplifiers is restricted due to nonlinear pulse distortions, which are enforced by the large product of intensity and interaction length inside the fiber core. This limitation can be overcome by sufficient pulse stretching in the time domain and the enlargement of the mode-field diameter of the fiber to reduce the nonlinear effects such as stimulated Raman scattering (SRS) and self-phase modulation (SPM). The application of this technique leads to a chirped-pulse amplification (CPA) system based on large-mode-area fibers (LMA), where power scaling is limited by the maximum acceptable phase distortion due to selfphase modulation.

Rare-earth-doped LMA photonic crystal fibers combine the advantages of an extended mode field area of an intrinsically single-mode core and an air-clad PCF with very high pump core NA. Using these fibers, we demonstrated a LMA fiber CPA system with $950 \mathrm{~W}$ of average power at $78 \mathrm{MHz}$ pulse repetition frequency with excellent beam quality. The pulses are efficiently compressed to $640 \mathrm{fs}$ pulse duration and $830 \mathrm{~W}$ of average power. In optimising the peak power, pulse energies up to $1 \mathrm{~mJ}$ at femtosecond pulse duration have been demonstrated. The current status and perspectives of ultrafast fiber laser systems and the application in production technology will be reviewed.

Andreas Tünnermann received the diploma and $\mathrm{PhD}$ degrees in physics from the University of Hannover in 1988 and 1992, respectively. His habilitation was related to topics on ultrastable light sources for interferometric gravitational wave detectors.

In the beginning of 1998 he joined the Friedrich-Schiller-University in Jena, Germany as a Professor and Director of the Institute of Applied Physics. In 2003 he became the Director of the Fraunhofer Institute of Applied Optics and Precision Engineering in Jena.

He is known for his pioneering work in fiber laser technology and the application of high power femtosecond lasers for materials processing.

Professor Tünnermann's research activities on optics and applied quantum electronics have been awarded with the Roentgen-Award 1997, WLT-Award 1998, Otto-Schott-Award 2003, Leibinger Innovation Award 2004 and the Gottfried-Wilhelm-Leibniz-Award 2005.

Impact of High Power Fiber Lasers on Materials Processing Market, Tim Webber, IPG Photonics, USA 
This presentation will review the current status of fiber technology, especially power levels, beam properties, and product configurations. This will be followed by a description of successful applications in the transportation, medical, and microelectronics industries at power levels from 200 watts to 20,000 watts. This presentation will conclude with a look forward to fiber technology's future applications at power levels of 30,000 watts to 50,000 watts.

Tim Webber, Market Development Manager at IPG Photonics, has been a contributor to the industrial laser technology since 1983. The author of nearly thirty technical articles published in leading professional journals or professional conference proceedings, Tim also contributed a chapter to a widely-used textbook, Laser Materials Processing (1996). Tim is a Manufacturing Engineering graduate of the College of Engineering, University of California at Berkeley.

High Power Ceramic Laser Technology, Prof. Ken-ichi Ueda, Inst. for Laser Science, Univ. of Electro-Communications (ILS/UEC), Japan

New technology on ceramic fabrication from nano-crystalline powder created new generation of solid state lasers. Ceramic lasers demonstrated higher power and higher efficiency in $\mathrm{CW}$ mode performance than single crystalline lasers. New concept of combined active media amplification allowed to generate ultrashort pulse generation from LD-pumped ceramic lasers with high efficiency. The review of ceramic laser technology and

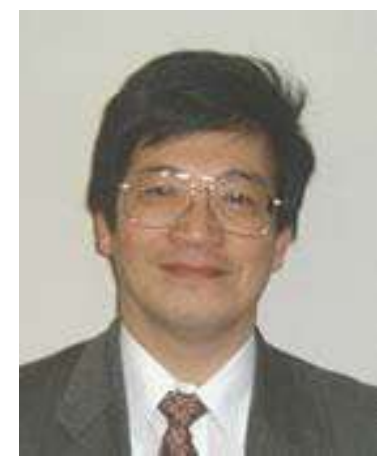
future prospects will be discussed.

Ken-ichi Ueda was born in Osaka in 1946. He received the BS and MS degrees from Osaka University and DrSci degree from the University of Tokyo.

After research works in R\&D center of JEOL, and the Physic Department of Sophia University in Tokyo, he joined the Institute for Laser Science at University of Electro-Communications in 1981. In ILS/UEC he investigated a large scale excimer laser system for laser fusion and ultrashort and ultra-high peak power lasers. In 1990 he began to develop an ultra-stabilized laserdiode-pumped solid laser and ultra-high quality optics for gravitational wave antenna. He developed $\mathrm{kW}$-output fiber-embedded disk lasers for industrial applications. He is a pioneer of ceramic lasers. He demonstrated $0.5 \mathrm{~W}$ and $60 \%$ efficiency in 1999, and demonstrated $1.5 \mathrm{~kW}$ output from Nd:YAG ceramics in 2002. In 2004 he reported a ceramic laser achieved better performance than a single crystalline laser for the first time. He has proposed many new ideas on solid state lasers and their applications.

Infrared and Green High-Power Lasers for Material Processing, $D r$. Michael von Borstel, Vice President of Research and Development and Operations, TRUMPF Laser and Systemtechnik GmbH, Germany

TRUMPF Group is a company which develops and manufactures highpower lasers for material processing. In this talk new developments by TRUMPF in the field of high-power $\mathrm{CO}_{2}$ and disk lasers will be presented:

- $\mathrm{A} \mathrm{CO}_{2}$ laser with cw power up to $50 \mathrm{~kW}$.

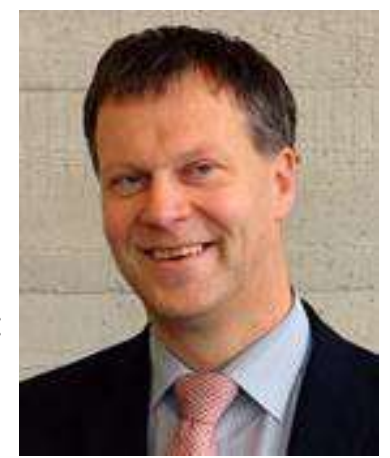


- A Yb:YAG disk laser with cw power up to $20 \mathrm{~kW}$.

- An intracavity-frequency doubled Yb:YAG thin-disk laser with $700 \mathrm{~W}$ at a repetition rate of 100 $\mathrm{kHz}$.

Dr. Michael von Borstel studied Physics at the Universitiy of Giessen (Germany) and graduated as Diplom-Physiker. In 1987 he received his doctorate in Physics with a dissertation in the field of laser spectroscopy.

Since 1988 Dr. von Borstel has been Head of the $\mathrm{CO}_{2}$-Development Department of TRUMPF Lasertechnik GmbH in Ditzingen (Germany). In 2003 he became Vice President of Research and Development and Operations at TRUMPF Laser- und Systemtechnik $\mathrm{GmbH}$.

High Energy Lasers: New Tools for Industrial Applications, $D r$. Edward F. Stephens, Director of Engineering, Northrop GrummanCutting Edge Optronics, USA

Decades of research and development in the military and aerospace industry have produced diode pumped high energy lasers capable of being used as directed energy weapons. Continuously pushing the limits of laser technology, these programs have now achieved greater than $100 \mathrm{~kW} \mathrm{CW}$ with good beam quality. In parallel, manufacturing industries have demanded and developed unprecedented laser system reliability thus enabling their broad adoption across many manufacturing sectors. This presentation discusses examples of how high energy lasers that satisfy the needs of both industries have and will continue to enable new technologies for the foreseeable future.

Dr. Edward Stephens is currently the Deputy General Manager at Northrop Grumman's Cutting Edge Optronics division based in St. Charles, Missouri. Since joining the company in 1996, he has held many positions including Director of Engineering, Director of Product Development, and Director of Semiconductor Packaging. He has been involved in all aspects of research, development, manufacturing, and marketing semiconductor lasers and diode pumped solid state lasers at the company. He has written numerous papers and presentations on semiconductor and solid state lasers and holds more than 25 patents in the area of semiconductor laser packaging and cooling.

Previous to Cutting Edge Optronics, Dr. Stephens worked in the McDonnell Douglas semiconductor laser group in St. Louis, MO. At McDonnell Douglas, he performed both theoretical and experimental research in the area of high-powered semiconductor arrays. Dr. Stephens received his $\mathrm{PhD}$ in Atomic Physics from University of Missouri-Rolla. 
Threat Detection, Eric Takeuchi, Director of Business Development, Daylight Solutions, USA, Moderator

The threats from global terrorism continue to evolve. Both at home and abroad, the lives of our soldiers and citizens are continually at risk from attack. Photonics technologies are starting to play an increasing role in detecting and defeating a multitude of current and emerging threats. Standoff detection of explosives and chemical agents, infrared imaging surveillance and aircraft protection are only a few of the applications in which photonics plays an enabling role. This panel will review a diverse

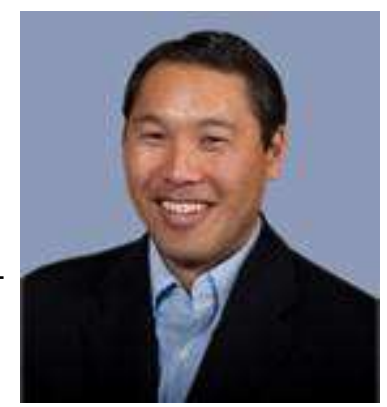
cross section of these topics and provide perspectives on the future growth of photonics technologies in these applications.

\section{Speakers:}

Optical Method for Standoff and Contact Detection of Explosives, Adam Bingham, Research Scientist, ICx Technologies, USA

Explosive threats present a variety of challenges for detection at both trace and bulk levels. Optical technologies, such as Raman spectroscopy, chemiluminescence, and hyperspectral imaging provide enabling capabilities for detecting threat signatures in both contact and standoff geometries. Current state of the art methods for standoff and contact detection of explosives will be discussed, and the current challenges facing explosives detection will be explored.

Dr. Bingham received his BS in Optical Engineering from the University of Rochester and his $\mathrm{PhD}$ in Photonics from Oklahoma State University. After graduation, he joined ICx Technologies, where his work has focused on Raman and infrared spectroscopy for standoff and contact identification of explosives, TICs/TIMs and other hazardous materials. Dr. Bingham has designed and built standoff detection systems based upon Raman, IR and fluorescence technologies. Dr. Bingham's previous research involved designing and testing far-IR (THz) integrated optics for sensing applications. These devices, including filters, waveguides and resonators utilized lithographically fabricated photonic crystal technology.

\section{Remote Detection and ID of Explosive and Chemical Threats, Price} Kagey, Vice President, Advanced Technology; Surface Optics Corp., USA

We discuss two topics: (1) Battlefield chemical and explosive threats, and (2) specific E-O detection techniques for threat associated vapors and residues.

(1) Threats such as homemade explosives (HME's) and ammonium nitrate/fuel oil (ANFO) have relatively high vapor pressures, and are thus candidates for E-O exploitation, as are many chemical threats. (2) Surface Optics Corporation (SOC) develops and manufactures real-time VNIR-LWIR hyperspectral (HS) imagers, whose utility for remote explosive residue detection is being investigated with some positive results in the 1-2.7 micron band. SOC plans experiments with their imaging FTIR, ImageFTIR. SOC's 
120/240 band VNIR imagers provide reliable vehicle/container tracking and locating, but as yet SOC hasn't seen reliable VNIR spectra associated with these threats. Laser wave mixing research shows promise for in-situ detection of vapors and with appropriate imaging system, remote detection. The increasing availability of higher power tunable QCLs provides both reliable target species detection and identification.

While serving in the 82nd Airborne Division Dr Kagey considered physics as an attractive alternative to night jumps. After receiving a $\mathrm{PhD}$ in theoretical physics from Temple University he joined The Aerospace Corporation and modeled nuclear effects and developed and modeled RF penetration aids for Minuteman II/III. This was followed by 10 years in the Central Intelligence Agency serving as a SIGINT specialist, operations officer, and as branch, division, and group chiefs. In addition to SIGINT he became increasingly involved with a variety of E-O related activities(MASINT). His career in industry includes the development of both RF and E-O collection and exploitation technologies and techniques; UV through LWIR and HF through 115 $\mathrm{GHz}$ (CO emissions). Prior to joining Surface optics Corporation Dr Kagey was a Senior Fellow at Lockheed Martin where he sponsored research in some of the techniques discussed today.

The Role of Optical-Based Sensors in Security, Tim Rayner, EU Government Affairs Technical Director, Rapiscan Systems Ltd., UK

The methods and technologies used to ensure the safety of the travelling public have not changed much since the 1970s. Checkpoints are routinely used at airports and other high value buildings, with surveillance used in other scenarios such as mass transit. However as recent events have shown, new methods and technologies need to be introduced to ensure the continued safety of the traveler. Aviation checkpoints are currently undergoing a significant improvement program to counter non-metallic person borne threats. However these improvements come at the cost of reductions to the flow of commerce which is problematic for the transport system and traveler alike. New approaches are required that allow for an acceptable level of security, but with minimal interruption to the flow of commerce. Standoff threat detection holds out the promise of achieving such an outcome by means of optical techniques, which are at the forefront of developments in this area. Rapiscan is responding and developing processes and technologies to provide effective security with minimal disruption to the flow of commerce.

Prior to joining Rapiscan Systems, Ltd., as Director of Advanced Technology, Dr. Rayner was Director of Business Development for Daylight Solutions, Inc. Before this he worked in senior research and development roles at QRSciences, General Electric, InVision Technologies and Quantum Magnetics. Dr. Rayner has twenty-two years experience in the security business, developing technologies and sensors for various applications based on quadrupole resonance (QR), magnetic resonance (MR), computed tomography (CT) and mid-IR absorption spectroscopy At Daylight Solutions, Inc., his role was to build a viable government funded research business focusing on the development of optical standoff threat detection and imaging technologies. He was responsible for winning a number of key awards from the US Army, the US Department of Energy and the Environmental Protection Agency (EPA). While at QRSciences, as Chief Technology Officer, his role was to consider technology development for 
the company and in this role developed a new product line focused on non-invasive weapons detection in baggage as well as continuing to push the state of the art with quadrupole resonance for explosive detection in a variety of scenarios including cargo, personnel and vehicles. He was responsible for executing over \$35 million dollars worth of US Government funded programs resulting in technologies and solutions for aviation checkpoint, baggage, cargo, vehicles and infrastructure. Dr. Rayner holds a BS and PhD degrees from King's College, University of London in Physical Chemistry.

\section{Biophotonics}

From the Lab to Market: Commercialization of Biophotonics IP, Keshav Kumar, Product Marketing Manager, Newport Corp., USA, Moderator

Biophotonics has evolved as one the active interdisciplinary area of research in the last decade of 20th century and shows an even greater potential for the 21 st century. The development of efficient and stable light sources and many other optical components and systems has been a major catalyst behind this evolution. The usage of these new era components has helped researchers to understand the complicated biological molecules by measuring its interaction with light generated from variety of light sources. Getting a clear image of biomolecules on sub nanometer scale and understanding the molecular level dynamics on different timescales ranging from seconds to femtosecond scale has received most focus in recent times. The belief lies behind understanding the biomolecules and its time resolved dynamics that will allow us to diagnose the disease in very early stage and also help us in developing more effective medicines for different diseases arising from undesired molecular compositions and dynamical motions. However, this development in technology and its usage to understand biomoelcues would not have been effective without the great collaboration between researchers in university and industry who worked hard towards making this commercially available for betterment of human health. In this session we will focus on the upcoming technologies and solutions that will allow us to decipher the structure, kinetic and dynamical motion of biomolecules in greater detail and put us one step further in direction of better diagnosis and personalized medicine.

\section{Speakers:}

Skin Diagnostics: A Global Solution, Raj Chhibber, CEO, BrighTex BioPhotonics LLC, USA

Quantification of skin conditions for developing new skin products, carrying out product studies for efficacy and safety by the independent labs. Formulating customized cosmetic for the end user and prescribing products and cosmetic treatments based on global skin conditions measured.

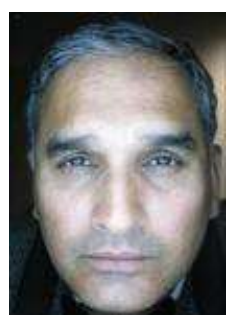


Raj Chhibber, CEO, BrighTex Bio-Photonics LLC, San Jose, California, US has 25 years experience in the Silicon Valley developing metrology equipment for the Semiconductor industry. He has held Senior management positions including engineering, research, and development at Nanometrics, Phase-Metrics, Therma-Wave, Micro Lithography, Eastman Kodak. He is the founder of many start up companies in the semiconductor metrology Technology sector and now a founder of BrigTex Bio-Photonics; the leader in Skin diagnostics for the cosmetic Industry. He earned a BSc and MS in Applied Physics from University of Essex, UK. He also received a Diploma in applied Physics from the Institute of Physics UK.

What Is Holding Back Ultrafast Laser Applications? Marcos Dantus, President and CEO of BioPhotonic Solutions Inc. and Distinguished Professor at Michigan State Univ., USA

Ultrafast lasers are critical for a number of biophotonic applications including two-photon imaging, corrective eye surgery, and even proteomics. In general, shorter pulses yield better results. Presently, the most significant technical bottle neck is delivering reliable ultrashort pulses to the target. This task requires accurate measurement of nonlinear optical dispersion and compensation. Biophotonic Solutions Inc. has developed the award winning MIIPS technology which seamlessly incorporates measurement and compression to deliver transform limited pulses. MIIPS has successfully compressed most ultrafast laser sources including those using supercontinuum from PCF fibers. We will present the latest developments in automated pulse compression from Biophotonic Solutions and discuss how these advances eliminate the need for manual tweaking, significantly reduce the cost of design, manufacture and operation of ultrafast lasers, and finally enable scientific research.

Dr. Dantus received his PhD in Chemistry (1991 Caltech) on the development of Femtochemistry, and his postdoctoral work on the development of Ultrafast Electron Diffraction under Professor Zewail (1999 Nobel Prize). He is a University Distinguished Professor of Chemistry and Physics at Michigan State University. His interests include ultrafast laser pulse theory and design, control of nonlinear laser-matter interactions, and biomedical imaging. Dantus has more than 150 publications, 43 invention disclosures and 13 patents related to the characterization, compression and applications of ultrashort shaped laser pulses in the areas of nonlinear optics, communications, biomedical imaging, and analytical chemistry instruments. Dantus has started three companies and is presently serving as the President and CEO of BioPhotonic Solutions Inc. Dantus is the President of the OSA Ann Arbor, MI chapter and serves on the board of advisors for Chemical Physics Letters.

Advancements of Ultrafast Lasers for Multiphoton Microscopy, Arnd Krueger, Senior Director of Strategic Marketing, Newport SpectraPhysics, USA

The development of compact, fully automated and widely wavelengthtunable ultrafast lasers has triggered an explosive growth in their use in a broad array of multiphoton microscopy techniques. Over the past decade

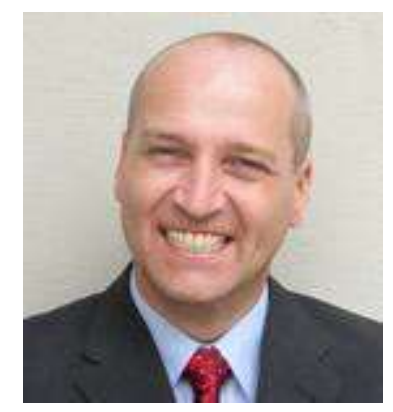


laser manufacturers have constantly improved the performance characteristics of these sources to meet the requirements of the biomedical user community for live cell imaging with longer cell viability and deeper tissue penetration. We will review the latest advances at Newport SpectraPhysics in the development of lasers and supporting systems for nonlinear microscopy, and discuss how they benefit the end user and progress application development.

Dr. Arnd Krueger is currently Senior Director of Strategic Marketing at Newport Corporation in Santa Clara, California, responsible for the company's Life \& Health Sciences and Research markets. Prior to his current appointment, Arnd was leading the team of Product Managers, Product Specialists, and Application Engineers as Senior Director of Marketing at SpectraPhysics, which since 2004 has been a Division of Newport Corporation. Earlier he was in charge of a cross-functional team of marketing, factory service, and engineering, focusing on growth opportunities and products in the ultrafast laser market. Arnd joined the German subsidiary of Spectra-Physics in 1995 and transferred to the company's California headquarters in 1999, holding a variety of positions in marketing, product management, and technical sales. Born and raised in Germany, Arnd received his PhD in Physics from the University of Düsseldorf in 1994. Subsequently he worked as a post-doctoral fellow at the University of Leiden in Netherlands.

\section{Liquid Array for Proteomic Analysis, Bao Nguyen, Director of R\&D, Arrayomics Inc., USA}

There is an increasing demand for accurate and cost-effective high multiplex platform for quantitative protein analysis. The most commonly used systems involve either a 2-D microarray or liquid based microbeads. Separately, these systems have significant limitations and advantages. Our ArrayableESPTM platform combines the high multiplexing capabilities and design adaptability of the 2-D arrays with the resilience and flexibility of the bead-based arrays. Protein and DNA based assays have been successfully carried out on our particles as small as 20x30x3 microns. This talk will focus on the detection methods, in junction with ArrayableESPTM platform, that would enable overcome current plexing limitations.

Bao Nguyen received his BS in Bioengineering from University of California, San Diego and his MS in Mechanical Engineering from San Diego State University. As Director of R\&D at Arrayomics, he is involved with designing and manufacturing ArrayableESP ${ }^{\mathrm{TM}}$ platform, optical detection system, as well as assay development. Prior to joining Arrayomics, Mr. Nguyen studied cartilage regeneration and tissue engineering at Shiley Center for Orthopedics Research and Education at Scripps Clinic.

Why Biophotonics Can Help Find Cures to Diseases, Quoc-Thang Nguyen, CEO, FemtoScience, USA

Pharmaceutical companies (-pharmas\|) will experience a severe loss of revenues in the next few years. The patent of their currently marketed drugs will expire soon and their drug pipeline is running dry. Their internal $\mathrm{R} \& \mathrm{D}$ is shut down to reduce costs. To overcome this situation, pharmas increasingly outsource drug development to smaller partners. These companies often rely on specific proprietary technologies to

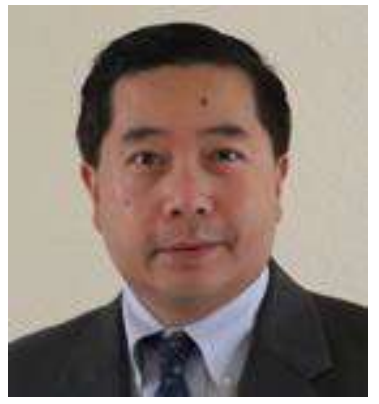


accelerate drug development. There is a window of opportunity for biophotonics entrepreneurs to enter new markets worth tens of billions of dollars.

Quoc Thang Nguyen is the founder and CEO of FemtoScience, a biotech startup that uses biophotonics to find cures for brain diseases such as Alzheimer's, schizophrenia, epilepsy and nicotine addiction. Femtoscience relies on a novel assay to detect specific brain chemicals called neurotransmitters. This IP-protected technique was invented by Quoc while he was a NIHfunded scientist in the Physics Department at UCSD. Quoc has a BS in engineering, a MS in Molecular Biophysics from the University Paris VI and a $\mathrm{PhD}$ in neuroscience from the University of California Irvine. Quoc won the Ralph Gerard Prize and is a Grass Fellow.

\section{Photonics for Energy}

Why the Solar Industry Excites Photonics and Laser Suppliers, Dr. Tony Hoult; General Manager, IPG Photonics, USA, Moderator

Lasers and solar photovoltaic (_PV') cells are often top-10 listings when scientific breakthroughs of the twentieth century are compiled; all the more topical considering they share both theoretical origins (embedded in quantum theory of the early 1900s) and world-firsts announced at the Bell

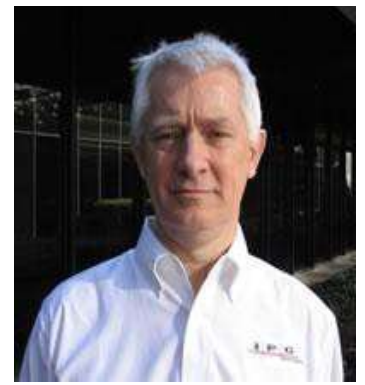
Laboratories during the 1950s. But increasing progress worldwide towards aggressive ecological targets on emissions-coupled with advances in low-cost manufacturing of high-efficiency solar panels-has propelled the solar industry in size (revenues, employees) way ahead of the laser industry. Market trends however within the laser and solar industries have become somewhat interwoven. Solar manufacturers are constantly finding new applications for laser-based tools: conversely, laser manufacturers are accelerating new product developments of _solar-specific“ laser sources. This session includes a diverse range of speakers to provide their perspectives on the relevant technical background and emerging market trends impacting on future laser source adoption within the solar industry.

\section{Speakers:}

Recent Advances in Laser Tools for Photovoltaic Manufacturing, David Clark, Senior Director, Strategic Marketing - Photovoltaics, Newport Corp./Spectra-Physics, USA

Solar in California: Policy and Technical Overview, Jurgen Daniel, Senior Scientist, Palo Alto Research Center, USA

Solar technology is perceived as the most viable long-term solution to the future global energy demand.

Particularly, in regions such as California with abundant sunshine, solar technology has significant growth potential. Californian government policies have been put into place to foster solar technology and utilities are increasingly embracing solar installations as part of their 
alternative energy mix. California, and in particular the San Francisco Bay Area, has also been the breeding ground for many new solar technologies.

This presentation will focus on solar photovoltaics and review some of the recent policies and technological developments in California. Examples of technological advances from industry and academia will be given including first-, second- and third-generation photovoltaics.

Jurgen Daniel is Senior Scientist at the Palo Alto Research Center where his research includes printed electronics, display technologies, micro-electro-mechanical systems and photovoltaics. Previously, he worked at Oxford Instruments and at FEI Europe and in 1998 he was visiting scientist at the Matsushita Research Institute, Tokyo. He holds a Dipl. Phys. degree from the University of Erlangen-Nuremberg, Germany, and a PhD in electrical engineering from the University of Cambridge, UK. Jurgen Daniel is founder and president of the Silicon Valley Photovoltaics Society (SVPVS).

Laser Processes within Solar Manufacturing, Corey Dunsky, President, Aeos Consulting, Inc., USA

The Need for 3-D Surface Characterization in PV Solar Cell Manufacturing, Andrew Masters, Vice President, Strategic Marketing and Business Development, Metrology and Instrumentation Group, Veeco Instruments, USA

The solar energy industry has experienced dynamic growth over the last several years, due in part to factors such as high oil prices, government energy initiatives, and a growing worldwide awareness of the potential impact of greenhouse gas emissions and associated carbon footprints on the environment.

Multiple photovoltaic technologies are presently competing for share of this growing market from traditional -bulk\| crystalline silicon, through thin-film technologies including amorphous

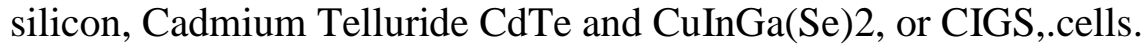

As with any industry, the key driver for commercial success is the overall cost to the end user, be it residential installations or grid-connected, utility-scale systems. While there are advantages and disadvantages to each of these technologies solar cell manufacturers are united in the goal to decrease the cost per kilowatt-hour for electricity over the life of the system. This cost can only go down if solar cell technologies continue to evolve.

Accurate 3-D surface metrology of key features is a critical to increasing solar cell efficiencies and improving yield, thereby decreasing manufacturing costs.

Andrew Masters is the Vice President of Strategic Marketing and Business Development for Veeco Instruments Metrology and Instrumentation Group. Prior to joining Veeco he was Director of Marketing for the OEM and Instrumentation markets at Coherent Inc. Between 2001 and 2005 Andrew held a number of positions within Coherent including Senior Business Development Manager - Microelectronics, North American Sales Manager for the Lambda Physik subsidiary and Sales Manager for Latin America and Australia. Prior to moving to the US 
in 2001 Andrew was the Sales and Marketing Manager for the Physical Sciences division within Coherent Scientific Pty Ltd. Andrew undertook his undergraduate studies in Math and Physics at the Flinders University of South Australia and PhD studies in the Laser Atomic Physics Group at Griffith University in Brisbane Australia.

Opportunities for Concentrating PV, Bill Kozlovsky, USA, Moderator

Large-scale commercial solar deployments are being planned with a wide array of alternative architectures. Concentrating Solar Power (CSP) system use focused sunlight to generate power via steam turbines and sterling engines. Concentrating Photovoltaic systems (CPV) use focused sunlight to reduce the amount of PV materials that are needed for electrical generation. In both CPV and CSP architectures, traditional optics and optical materials play critical roles. Reflective materials, coatings, Fresnel lenses, and secondary optics are key components to enabling efficient, low cost, and scalable solutions. This session will cover the demanding cost, performance, and reliability specifications needed for CPV and CSP components, as well as volume needs for their rapidly expanding deployments.

\section{Speakers:}

Title to Be Announced, Steve Horne, Chief Technical Officer, SolFocus, Inc., USA

Why Medium Concentration CPV? Eric Johnson, Co-founder and Director of Advanced Development, Skyline Solar, USA

As standard crystalline silicon PV modules are pushed down the price-volume curve by expanding Chinese capacity, and CSP projects are beginning to get financed again, what are the system level requirements for medium concentration CPV to de-risk and scale in a carbon-meaningful way?

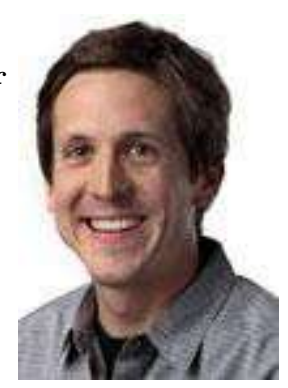

Eric co-founded Skyline Solar (with Bob MacDonald and Bill Keating) in 2007. Previously, he consulted for a variety of solar companies - both independently and as a Senior Engineer with GreenMountain Engineering, a consultancy focused on clean technology. Prior to GreenMountain, he was the MechE' at Phasebridge (aquired by Emcore) where he co-invented a bracket for laser welding photonics components with sub-micron accuracy. His career began in energy storage at Beacon Power, developing high performance (25,000 RPM) flywheel systems. Eric received his BS in Mechanical Engineering from Cornell.

Title to Be Announced, Wayne Miller, Vice President of Engineering, GreenVolts, Inc., USA

Mr. Miller has a proven 20-year track record designing groundbreaking solar and high technology products. Previously, he was Vice President of Product

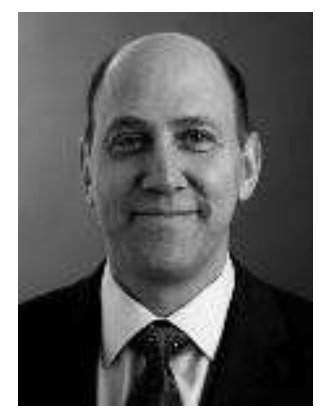


and BOS (Balance of System) Engineering at Solyndra where he led the company's product development and field operations team for their non-penetrating cylindrical CIGs thin film solar module. Additionally, he built and led the engineering team at SolFocus where he was responsible for the development of the company's original concentrating photovoltaic system. Prior, Mr. Miller spent 15 years designing products for high volume production at a number of global technology leading companies, including Credence Systems, Apple Computers, In Focus Systems and AT\&T Bell Labs.

Mr. Miller holds 19 patents and has led design on nine products that have been awarded International Design Excellence Awards while at Apple Inc, Credence Systems, and In Focus Systems. He holds a BS and a MS in Mechanical Engineering from Northeastern University

\section{Technology Transfer Showcase}

The CLEO Technology Transfer Program offers attendees from industry a -one-stop\| opportunity to learn about the latest optic and photonic technologies coming out of Universities and Government Labs. This is a great opportunity to hear speakers from top Optic and Photonic Universities talking about their institutions' latest research that could lead to new commercial products or improvements in the efficiency, durability and/or availability of existing components or systems. This Thursday afternoon session will also feature White Paper Posters as well as two case study speakers who will talk about how they successfully licensed technology from a University and transferred that research into a commercial product offered by their company.

\section{Short Course Schedule by Time}

Sunday, May 16, 2010

9:00 a.m.-6:00 p.m.

SC200 Laser Remote Sensing, Timothy Carrig, Phillip Gatt; Lockheed Martin, USA

10:00 a.m.-1:00 p.m.

SC189 Quantum-Enhanced Technologies, Ian Walmsley; Univ. of Oxford, UK

SC300 Silicon Photonics, Bahram Jalali; Univ. of California at Los Angeles, USA

SC301 Quantum Cascade Lasers: From Band Structure Engineering to

Commercialization, Federico Capasso; Harvard Univ., USA

SC336 Green Photonics, S. J. Ben Yoo; Univ. of California at Davis, USA

SC338 Fiber-Based Parametric Devices, Colin J. McKinstrie; Bell Labs, Alcatel-Lucent, USA 
2:00 p.m.-6:00 p.m.

SC154 Quantum Well Devices for Optics and Optoelectronics, David A. B. Miller; Stanford Univ., USA

Cancelled SC198 Packaging of Optoelectronic Components, Andreas Rose; Photonics Res. Corp., USA

SC271 Quantum Information-Technologies and Applications, Prem Kumar' ${ }^{\text {, Paul Toliver }}$;

${ }^{1}$ Northwestern Univ., USA, ${ }^{2}$ Telcordia, USA

NEW! SC352 Ultrafast Laser Pulse Shaping, Marcos Dantus; Michigan State Univ., USA

3:00 p.m.-6:00 p.m.

SC164 THz Technology, Matthew T. Reiten; Los Alamos Natl. Lab, USA

SC339 A Guide to Building an Optical Clock, Scott Diddams, Chris Oates; NIST, USA

Monday, May 17, 2010

8:30 a.m.-5:30 p.m.

SC136 Understanding Lasers and Critical Optical Components, Shaoul Ezekiel; MIT, USA

8:00 a.m.-12:00 p.m.

SC153 Quasi-Phasematching for Wavelength Conversion and All-Optical Nonlinear

Processing, Peter G. R. Smith; Univ. of Southampton, UK

SC182 Biomedical Optical Diagnostics and Sensing, Thomas Huser; Univ. of California at

Davis, USA

9:00 a.m.-12:00 p.m.

SC147 Optical Fiber Communication Systems, Alan Willner; Univ. of Southern California, USA

SC165 Laser Diode-Pumped Solid-State Lasers, Larry Marshall; Southern Cross Venture Partners, USA

SC302 MetaMaterials, Vladimir M. Shalaev; Purdue Univ., USA

1:30 p.m.-5:30 p.m.

SC149 Foundations of Nonlinear Optics, Robert Fisher; R. A. Fisher Associates, USA

SC160 Microwave Photonics, Keith Williams; NRL, USA

SC194 Photonic Crystal Fibers and Devices, Benjamin J. Eggleton; Univ. of Sydney, Australia SC316 Organic Photonic Devices, Marc Baldo, Vladimir Bulovic; MIT, USA 
SC333 Intellectual Property: Bringing Academic Invention to the Market, Nadya Reingand; Celight Inc., USA

Tuesday, May 18, 2010

8:30 a.m.-12:30 p.m.

SC157 Laser Beam Analysis, Propagation and Shaping Techniques, James R. Leger; Univ. of Minnesota, USA

SC163 Practical OPOs, Majid Ebrahim-Zadeh; Inst. Catalana de Recerca i Estudis Avançats, Inst. de Ciencies Fotoniques, Spain

SC167 Fundamentals of Semiconductor Lasers: Edge-Emitters to Micro Cavity Devices, Kent Choquettel, Weng Chow'; ' 'Univ. of Illinois, USA, ${ }^{2}$ Sandia Natl. Labs, USA

SC270 High Power Fiber Lasers and Amplifiers, W. Andrew Clarkson; Optoelectronics Res. Ctr., Univ. of Southampton, UK

9:30 a.m. $-12: 30$ p.m.

SC221 Nano-Photonics: Physics and Techniques, Axel Scherer; Caltech, USA

SC334 The Art of Modeling Optical Systems, Curtis Menyuk; Univ. of Maryland, Baltimore County, USA

SC337 Single Photon Detection Mark A. Itzler; Princeton Lightwave Inc., USA

1:30 p.m.-5:30 p.m.

Cancelled SC123 Erbium-Doped Fiber Amplifiers and Raman Fiber Amplifiers, John Zyskind; Mintera Corp., USA

Cancelled SC143 Introductory and Intermediate Topics in Polarized Light, Robert Fisher; R. A. Fisher Associates, USA

SC155 Ultrashort Laser Pulse Measurement, Pamela Bowlan; Georgia Tech, USA

Cancelled SC319 Quantum Dot Laser Diodes, Peter Blood; Cardiff Univ., UK

SC335 Super-Resolution Optical Microscopy, Stephen Lane ${ }^{12}$, Thomas Huser'; ' Lawrence Livermore Natl. Lab, USA, ${ }^{2}$ Univ. of California at Davis, USA

NEW! SC353 An Overview of R\&D Program Management, Michael T. Dehring, Lockheed Martin, USA 
Short Course Schedule by Topic Category

\section{Fundamental Optical Science and Technologies}

Cancelled SC143 Introductory and Intermediate Topics in Polarized Light, Robert Fisher; R. A. Fisher Associates, USA

SC157 Laser Beam Analysis, Propagation and Shaping Techniques, James R. Leger; Univ. of Minnesota, USA

SC333 Intellectual Property: Bringing Academic Invention to the Market, Nadya Reingand; Celight Inc., USA

SC334 The Art of Modeling Optical Systems, Curtis Menyuk; Univ. of Maryland, Baltimore County, USA

NEW! SC353 An Overview of R\&D Program Management, Michael T. Dehring, Lockheed Martin, USA

\section{CLEO 02: Solid-State, Liquid and Gas Lasers}

SC136 Understanding Lasers and Critical Optical Components, Shaoul Ezekiel; MIT, USA SC165 Laser Diode-Pumped Solid-State Lasers, Larry Marshall; Southern Cross Venture Partners, USA

\section{CLEO 03: Semiconductor Lasers}

SC167 Fundamentals of Semiconductor Lasers: Edge-Emitters to Micro Cavity Devices, Kent Choquettel, Weng Chow ${ }^{2}$; ${ }^{1}$ Univ. of Illinois, USA, ${ }^{2}$ Sandia Natl. Labs, USA

SC301 Quantum Cascade Lasers: From Band Structure Engineering to

Commercialization, Federico Capasso; Harvard Univ., USA

Cancelled SC319 Quantum Dot Laser Diodes, Peter Blood; Cardiff Univ., UK

\section{CLEO 04: Applications of Nonlinear Optics}

SC149 Foundations of Nonlinear Optics, Robert Fisher; R. A. Fisher Associates, USA SC153 Quasi-Phasematching for Wavelength Conversion and All-Optical Nonlinear Processing, Peter G. R. Smith; Univ. of Southampton, UK SC163 Practical OPOs, Majid Ebrahim-Zadeh; Inst. Catalana de Recerca i Estudis Avançats, Inst. de Ciencies Fotoniques, Spain

\section{CLEO 05: Terahertz Technologies and Applications}

SC164 THz Technology, Matthew T. Reiten; Los Alamos Natl. Lab, USA 


\section{CLEO 08: Ultrafast Optics, Optoelectronics and Applications}

SC155 Ultrashort Laser Pulse Measurement, Pamela Bowlan; Georgia Tech, USA

NEW! SC352 Ultrafast Laser Pulse Shaping, Marcos Dantus; Michigan

\section{CLEO 09: Components, Integration, Interconnects and Signal Processing}

SC154 Quantum Well Devices for Optics and Optoelectronics, David A. B. Miller; Stanford Univ., USA

SC160 Microwave Photonics, Keith Williams; NRL, USA

SC337 Single Photon Detection, Mark A. Itzler; Princeton Lightwave Inc., USA

\section{CLEO 10: Biophotonics and Optofluidics}

SC182 Biomedical Optical Diagnostics and Sensing, Thomas Huser; Univ. of California at Davis, USA

SC335 Super-Resolution Optical Microscopy, Stephen Lane ${ }^{1,2}$, Thomas Huser ${ }^{2}$ ' ${ }^{2}$ awrence Livermore Natl. Lab, USA, ${ }^{2}$ Univ. of California at Davis, USA

\section{CLEO 11: Fiber Amplifiers, Lasers and Devices}

Cancelled SC123 Erbium-Doped Fiber Amplifiers and Raman Fiber Amplifiers, John Zyskind; JDS Uniphase, USA

SC149 Foundations of Nonlinear Optics, Robert Fisher; R. A. Fisher Associates, USA SC194 Photonic Crystal Fibers and Devices, Benjamin J. Eggleton; Univ. of Sydney, Australia SC270 High Power Fiber Lasers and Amplifiers, W. Andrew Clarkson; Optoelectronics Res. Ctr., Univ. of Southampton, UK

SC338 Fiber-Based Parametric Devices, Colin J. McKinstrie; Bell Labs, Alcatel-Lucent, USA

\section{CLEO 12: Lightwave Communications and Networks}

SC147 Optical Fiber Communication Systems, Alan Willner; Univ. of Southern California, $U S A$

Cancelled SC198 Packaging of Optoelectronic Components, Andreas Rose; Photonics Res. Corp., USA

SC336 Green Photonics, S. J. Ben Yoo; Univ. of California at Davis, USA

\section{CLEO 13: Active Optical Sensing}


SC200 Laser Remote Sensing, Timothy Carrig, Phillip Gatt; Lockheed Martin, USA

\section{CLEO 14: Optical Metrology}

SC339 A Guide to Building an Optical Clock, Scott Diddams, Chris Oates; NIST, USA

\section{CLEO 15: LEDS, Photovoltaics and Energy-Efficient (-Green\|) Photonics}

SC316 Organic Photonic Devices, Marc Baldo, Vladimir Bulovic; MIT, USA

\section{CLEO 16: Micro- and Nano-Photonics Devices}

SC300 Silicon Photonics, Bahram Jalali; Univ. of California at Los Angeles, USA

\section{QELS 02: Quantum Science, Engineering and Technology}

SC189 Quantum-Enhanced Technologies, Ian Walmsley; Univ. of Oxford, UK

SC271 Quantum Information-Technologies and Applications, Prem Kumar; Northwestern Univ., USA

\section{QELS 03: Metamaterials and Complex Media}

SC302 MetaMaterials, Vladimir M. Shalaev; Purdue Univ., USA

\section{QELS 04: Optical Interactions with Condensed Matter and Ultrafast Phenomena}

SC149 Foundations of Nonlinear Optics, Robert Fisher; R. A. Fisher Associates, USA

\section{QELS 05: Nonlinear Optics and Novel Phenomena}

SC149 Foundations of Nonlinear Optics, Robert Fisher; R. A. Fisher Associates, USA

\section{QELS 06: Nano-Optics and Plasmonics}

SC221 Nano-Photonics: Physics and Techniques, Axel Scherer; Caltech, USA 